\title{
Model results of $\mathrm{OH}$ airglow considering four different wavelength regions to derive night-time atomic oxygen and atomic hydrogen in the mesopause region
}

\author{
Tilo Fytterer ${ }^{1}$, Christian von Savigny ${ }^{2}$, Martin Mlynczak ${ }^{3}$, and Miriam Sinnhuber ${ }^{1}$ \\ ${ }^{1}$ Institute for Meteorology and Climate Research, Karlsruhe Institute of Technology, \\ 76344 Eggenstein-Leopoldshafen, Germany \\ ${ }^{2}$ Institute of Physics, University of Greifswald, 17489 Greifswald, Germany \\ ${ }^{3}$ Langley Research Center, NASA, Hampton, Virginia 23681-2199, USA
}

Correspondence: Miriam Sinnhuber (miriam.sinnhuber@kit.edu)

Received: 22 July 2018 - Discussion started: 6 August 2018

Revised: 14 January 2019 - Accepted: 17 January 2019 - Published: 12 February 2019

\begin{abstract}
Based on the zero-dimensional box model Module Efficiently Calculating the Chemistry of the Atmosphere/Chemistry As A Box model Application (CAABA/MECCA-3.72f), an $\mathrm{OH}$ airglow model was developed to derive night-time number densities of atomic oxygen $\left(\left[\mathrm{O}\left({ }^{3} \mathrm{P}\right)\right]\right)$ and atomic hydrogen $([\mathrm{H}])$ in the mesopause region $(\sim 75-100 \mathrm{~km})$. The profiles of $\left[\mathrm{O}\left({ }^{3} \mathrm{P}\right)\right]$ and $[\mathrm{H}]$ were calculated from $\mathrm{OH}$ airglow emissions measured at $2.0 \mu \mathrm{m}$ by the Sounding of the Atmosphere using Broadband Emission Radiography (SABER) instrument on board NASA's Thermosphere Ionosphere Mesosphere Energetics and Dynamics (TIMED) satellite. The two target species were used to initialize the $\mathrm{OH}$ airglow model, which was empirically adjusted to fit four different $\mathrm{OH}$ airglow emissions observed by the satellite/instrument configuration TIMED/SABER at $2.0 \mu \mathrm{m}$ and at $1.6 \mu \mathrm{m}$ as well as measurements by the Scanning Imaging Absorption Spectrometer for Atmospheric Chartography (SCIAMACHY) instrument on board the Environmental Satellite (ENVISAT) of the transitions $\mathrm{OH}(6-2)$ and $\mathrm{OH}(3-1)$. Comparisons between the "best-fit model" obtained here and the satellite measurements suggest that deactivation of vibrationally excited $\mathrm{OH}(v)$ via $\mathrm{OH}(v \geq 7)+\mathrm{O}_{2}$ might favour relaxation to $\mathrm{OH}\left(v^{\prime} \leq 5\right)+\mathrm{O}_{2}$ by multi-quantum quenching. It is further indicated that the deactivation pathway to $\mathrm{OH}\left(v^{\prime}=v-5\right)+\mathrm{O}_{2}$ dominates. The results also provide general support of the recently proposed mechanism $\mathrm{OH}(v)+\mathrm{O}\left({ }^{3} \mathrm{P}\right) \rightarrow \mathrm{OH}\left(0 \leq v^{\prime} \leq v-5\right)+\mathrm{O}\left({ }^{1} \mathrm{D}\right)$ but suggest slower rates of $\mathrm{OH}(v=8,7,6,5)+\mathrm{O}\left({ }^{3} \mathrm{P}\right)$, partly disagreeing with laboratory experiments. Additionally, deacti-
\end{abstract}

vation to $\mathrm{OH}\left(v^{\prime}=v-5\right)+\mathrm{O}\left({ }^{1} \mathrm{D}\right)$ might be preferred. The profiles of $\left[\mathrm{O}\left({ }^{3} \mathrm{P}\right)\right]$ and $[\mathrm{H}]$ derived here are plausible between 80 and $95 \mathrm{~km}$ but should be regarded as an upper limit. The values of $\left[\mathrm{O}\left({ }^{3} \mathrm{P}\right)\right]$ obtained in this study agree with the corresponding TIMED/SABER values between 80 and $85 \mathrm{~km}$ but are larger from 85 to $95 \mathrm{~km}$ due to different relaxation assumptions of $\mathrm{OH}(v)+\mathrm{O}\left({ }^{3} \mathrm{P}\right)$. The $[\mathrm{H}]$ profile found here is generally larger than TIMED/SABER $[\mathrm{H}]$ by about $50 \%$ from 80 to $95 \mathrm{~km}$, which is primarily attributed to our faster $\mathrm{OH}(v=8)+\mathrm{O}_{2}$ rate.

\section{Introduction}

Atomic oxygen in its ground state $\left(\mathrm{O}\left({ }^{3} \mathrm{P}\right)\right)$ and atomic hydrogen $(\mathrm{H})$ strongly influence the energy budget in the mesopause region $(\sim 75-100 \mathrm{~km})$ during the day and at night (Mlynczak and Solomo, 1993), and consequently affect atmospheric air temperature, wind, and wave propagation (Andrews et al., 1987). Therefore, an improved knowledge of the abundance of $\mathrm{O}\left({ }^{3} \mathrm{P}\right)$ and $\mathrm{H}$ is of great importance when studying the mesopause region. At these altitudes, $\mathrm{O}\left({ }^{3} \mathrm{P}\right)$ has a direct impact on the heating rates by participating in several exothermic chemical reactions (Mlynczak and Solomon, 1993, their Table 4). But $\mathrm{O}\left({ }^{3} \mathrm{P}\right)$ also contributes to radiative cooling by exciting $\mathrm{CO}_{2}$ via collisions, leading to increased infrared emissions of $\mathrm{CO}_{2}$ and partly opposing the $\mathrm{O}\left({ }^{3} \mathrm{P}\right)$ chemical heating effect. Night-time $\mathrm{H}$ plays a crucial 
role in the mesopause region due to the destruction of ozone $\left(\mathrm{O}_{3}\right)$, which is accompanied by the release of a considerable amount of heat (Mlynczak and Solomon, 1993). This chemical reaction additionally leads to the production of vibrationally excited hydroxyl radicals $(\mathrm{OH}(v>0))$ up to the vibrational level $v=9$, causing the formation of $\mathrm{OH}$ emission layers in the atmosphere (Meinel bands; Meinel, 1950).

Direct measurements of $\mathrm{O}\left({ }^{3} \mathrm{P}\right)$ and $\mathrm{H}$ are relatively rare because as atomic species they do not have observable vibration-rotation spectra. Consequently, measuring these species in the mesopause region by remote sensing requires complex methods, while in situ observations are rather expensive (e.g. Mlynczak et al., 2004; Sharp and Kita, 1987). Thus, no global data set based on direct observations exists. As a consequence, an indirect method was introduced by Good (1976) to derive $\left[\mathrm{O}\left({ }^{3} \mathrm{P}\right)\right]$ and $[\mathrm{H}]$ during the night, using $\mathrm{OH}$ airglow emissions. This approach was also adapted by Mlynczak et al. (2013a, 2014, 2018) which derived a global data set of night-time $\left[\mathrm{O}\left({ }^{3} \mathrm{P}\right)\right]$ and $[\mathrm{H}]$ in the mesopause region from satellite observations of $\mathrm{OH}(v)$. The method is based on the assumption of chemical steady state of $\mathrm{O}_{3}$ and further depends on several radiative lifetimes, chemical reactions, and physical processes involving $\mathrm{OH}(v)$. However, the corresponding total rate coefficients and branching ratios are still not sufficiently known, and thus present a large source of uncertainty in the derivation of $\left[\mathrm{O}\left({ }^{3} \mathrm{P}\right)\right]$ and $[\mathrm{H}]$.

There are two major issues currently discussed in the literature which considerably affect the overall abundance of derived $\mathrm{O}\left({ }^{3} \mathrm{P}\right)$ and $\mathrm{H}$. The first problem addresses the underlying deactivation schemes of $\mathrm{OH}(v)$ from the higher excited state $v$ to the lower excited state $v^{\prime}\left(v^{\prime}<v\right)$ through collisions with $\mathrm{O}_{2}$. This can generally occur via sudden death $\left(\mathrm{OH}(v)+\mathrm{O}_{2} \rightarrow \mathrm{OH}\left(v^{\prime}=0\right)+\mathrm{O}_{2}\right)$, singlequantum $\left(\mathrm{OH}(v)+\mathrm{O}_{2} \rightarrow \mathrm{OH}\left(v^{\prime}=v-1\right)+\mathrm{O}_{2}\right)$, or multiquantum $\left(\mathrm{OH}(v)+\mathrm{O}_{2} \rightarrow \mathrm{OH}\left(v^{\prime}<v\right)+\mathrm{O}_{2}\right)$ quenching. However, in case of the sudden death approach, it is still unknown where such a huge amount of excess energy is transferred. The second crucial point comprises the deactivation scheme and the total rate of $\mathrm{OH}(v)+\mathrm{O}\left({ }^{3} \mathrm{P}\right)$, including the new pathway $\mathrm{OH}(v)+\mathrm{O}\left({ }^{3} \mathrm{P}\right) \rightarrow \mathrm{OH}\left(0 \leq v^{\prime} \leq v-5\right)+\mathrm{O}\left({ }^{1} \mathrm{D}\right)$ suggested by Sharma et al. (2015).

Over the last 3 to 4 decades, several model studies attempted to fit $\mathrm{OH}$ airglow measurements using different rates and schemes for the deactivation of $\mathrm{OH}(v)$ by $\mathrm{O}_{2}$ and by $\mathrm{O}\left({ }^{3} \mathrm{P}\right)$. And at least to our knowledge, there is no general agreement about which model is correct. The deactivation of $\mathrm{OH}(v)$ by $\mathrm{O}_{2}$ in many models (e.g. von Savigny et al., 2012; Mlynczak et al., 2013a; Grygalashvyly et al., 2014; Panka et al., 2017) is based on the model proposed by AdlerGolden (1997). It assumes a combination of multi-quantum and single-quantum quenching and was derived from theoretical considerations and ground-based observations. $\mathrm{Xu}$ et al. (2012) investigated measurements from the Sounding of the Atmosphere using Broadband Emission Radiome- try (SABER) instrument on board the NASA Thermosphere Ionosphere Mesosphere Energetics and Dynamics (TIMED) satellite of the $\mathrm{OH}$ airglow emissions at $2.0 \mu \mathrm{m}$ and at $1.6 \mu \mathrm{m}$. Their results support the model of Adler-Golden (1997) but suggest slower total $\mathrm{OH}(v)+\mathrm{O}_{2}$ rates. They further exclude the sudden death mechanism as a possible deactivation scheme. There are also two theoretical studies (Shalashilin et al., 1995; Caridade et al., 2002) which investigated $\mathrm{OH}(v)$ deactivation via $\mathrm{O}_{2}$, both supporting a combination of multiquantum and single-quantum quenching similar to the model of Adler-Golden (1997).

However, Russell and Lowe (2003) and Russell et al. (2005) analysed $\mathrm{OH}(8-3)$ and $\mathrm{O}\left({ }^{1} \mathrm{~S}\right)$ airglow emissions measured by the Wind Imaging Interferometer (WINDII) instrument on board the Upper Atmospheric Research Satellite (UARS). Both airglow emissions were used to derive separate data sets of $\left[\mathrm{O}\left({ }^{3} \mathrm{P}\right)\right]$, and the best agreement between these two $\left[\mathrm{O}\left({ }^{3} \mathrm{P}\right)\right]$ data sets was obtained when a sudden death scheme for $\mathrm{OH}(v)+\mathrm{O}_{2}$ quenching was applied. Kaufmann et al. (2008) investigated several $\mathrm{OH}$ airglow spectra between 1 and $1.75 \mu \mathrm{m}$ measured by the Scanning Imaging Absorption Spectrometer for Atmospheric Chartography (SCIAMACHY) instrument on board the Environmental Satellite (ENVISAT). They found the best agreement between their model and the measured $\mathrm{OH}$ airglow spectra when a combination of sudden death and single-quantum quenching was used.

Vibrationally dependent rates of $\mathrm{OH}(v)+\mathrm{O}\left({ }^{3} \mathrm{P}\right)$ were determined by Varandas (2004) and Caridade et al. (2013), using quasi-classical trajectory calculations. Their results suggest that deactivation occurs via a chemical reaction as well as multi-quantum quenching. Kalogerakis et al. (2011) obtained a deactivation rate of $\mathrm{OH}(v=9)+\mathrm{O}\left({ }^{3} \mathrm{P}\right)$ from laboratory experiments which is several times larger than the rate from these calculations. But applying this fast quenching rate led to non-physical $\left[\mathrm{O}\left({ }^{3} \mathrm{P}\right)\right]$ values and associated heating rates (Smith et al., 2010; Mlynczak et al., 2013a). Thus, Sharma et al. (2015) proposed a new mechanism $\mathrm{OH}(v)+\mathrm{O}\left({ }^{3} \mathrm{P}\right) \rightarrow \mathrm{OH}\left(0 \leq v^{\prime} \leq v-5\right)+\mathrm{O}\left({ }^{1} \mathrm{D}\right)$ to account for results from both theory and experiment. Very recent laser experiments and model studies support this new pathway, while the exact values of the branching ratios and total loss rates are still not known (Kalogerakis et al., 2016; Panka et al., 2017). However, recently published results by Mlynczak et al. (2018) oppose this mechanism. They also applied the new rate of Kalogerakis et al. (2011) for $\mathrm{OH}(v=9)+\mathrm{O}\left({ }^{3} \mathrm{P}\right)$. But in order to get the annual energy budget into near balance, it was necessary to assume that at least $\mathrm{OH}(v=$ 9) $+\mathrm{O}\left({ }^{3} \mathrm{P}\right)$ occurs via single-quantum relaxation. Additionally, the rate of $\mathrm{OH}(v=8)+\mathrm{O}_{2}$ had to be reduced and is considerably smaller than the value reported from AdlerGolden (1997).

The newly suggested rates of $\mathrm{OH}(v)+\mathrm{O}\left({ }^{3} \mathrm{P}\right)$ were applied in different models to derive $\left[\mathrm{O}\left({ }^{3} \mathrm{P}\right)\right]$ in the mesopause region. Mlynczak et al. (2018) used SABER OH air- 
glow emissions observed at $2.0 \mu \mathrm{m}$ to derive $\left[\mathrm{O}\left({ }^{3} \mathrm{P}\right)\right]$ and assumed rates of $3.0 \times 10^{-10}$ and $1.5 \times 10^{-10} \mathrm{~cm}^{3} \mathrm{~s}^{-1}$ for $\mathrm{OH}(v=9)+\mathrm{O}\left({ }^{3} \mathrm{P}\right)$ and $\mathrm{OH}(v=8)+\mathrm{O}\left({ }^{3} \mathrm{P}\right)$, respectively. They further stated that deactivation of $\mathrm{OH}(v=9)+\mathrm{O}\left({ }^{3} \mathrm{P}\right)$ has to occur via single-quantum quenching and that the $\mathrm{OH}(v=8)+\mathrm{O}_{2}$ rate has to be smaller than is known from laboratory measurements to get the global annual energy budget into near balance. Panka et al. (2018) simultaneously investigated SABER OH airglow emissions measured at 2.0 and $1.6 \mu \mathrm{m}$, while applying faster rates for $\mathrm{OH}(v=$ 8) $+\mathrm{O}\left({ }^{3} \mathrm{P}\right)$ and $\mathrm{OH}(v)+\mathrm{O}_{2}$. Their $\left[\mathrm{O}\left({ }^{3} \mathrm{P}\right)\right]$ values agree within the corresponding errors with the results reported by Mlynczak et al. (2018) above $\sim 87 \mathrm{~km}$ but are larger in the altitude region below. The authors also demonstrated the high sensitivity of the derived $\left[\mathrm{O}\left({ }^{3} \mathrm{P}\right)\right]$ from $\mathrm{O}\left({ }^{3} \mathrm{P}\right)$ quenching rates applied in their model. Zhu and Kaufmann (2018) analysed the SCIAMACHY OH(9-6) transition. They used a value of $2.3 \times 10^{-10} \mathrm{~cm}^{3} \mathrm{~s}^{-1}$ for $\mathrm{OH}(v=9)+\mathrm{O}\left({ }^{3} \mathrm{P}\right)$, which is lower than the one applied in the two previous studies, resulting in generally lower $\left[\mathrm{O}\left({ }^{3} \mathrm{P}\right)\right]$ values in the altitude region above $87 \mathrm{~km}$. Their rate for $\mathrm{OH}(v=9)+\mathrm{O}_{2}$ lies between the corresponding rates of the two other studies, and consequently their $\left[\mathrm{O}\left({ }^{3} \mathrm{P}\right)\right]$ is also between the $\left[\mathrm{O}\left({ }^{3} \mathrm{P}\right)\right]$ values of these two studies below $87 \mathrm{~km}$. Thus, recent publications indicate that the rate of $\mathrm{OH}(v=9,8)+\mathrm{O}\left({ }^{3} \mathrm{P}\right)$ might be slower than previously suggested in Sharma et al. (2015). But this problem needs further attention because all three papers derive different $\left[\mathrm{O}\left({ }^{3} \mathrm{P}\right)\right]$, depending on the data sets investigated.

In order to address the two major issues stated above, this paper is focused on the development of a zero-dimensional box model for atmospheric $\mathrm{OH}$ airglow with the intention to derive night-time $\left[\mathrm{O}\left({ }^{3} \mathrm{P}\right)\right]$ and $[\mathrm{H}]$ in the mesopause region. The model considers the formation of $\mathrm{OH}(v)$ via $\mathrm{H}+\mathrm{O}_{3}$ and the deactivation of $\mathrm{OH}(v)$ due to spontaneous emission of photons, chemical reactions, and physical collisions with the atmospheric air compounds $\mathrm{N}_{2}, \mathrm{O}_{2}$, and $\mathrm{O}\left({ }^{3} \mathrm{P}\right)$. We used the indirect method introduced by Good (1976) and derived night-time $\left[\mathrm{O}\left({ }^{3} \mathrm{P}\right)\right]$ and $[\mathrm{H}]$ from TIMED/SABER $\mathrm{OH}$ emissions at $\sim 2.0 \mu \mathrm{m}$, while also considering the $\mathrm{OH}$ airglow observations from TIMED/SABER at $\sim 1.6 \mu \mathrm{m}$ as well as the $\mathrm{OH}(6-2)$ and $\mathrm{OH}(3-1)$ transitions measured by ENVISAT/SCIAMACHY. Further sensitivity runs were carried out to estimate the uncertainty on the derived values of $\left[\mathrm{O}\left({ }^{3} \mathrm{P}\right)\right]$ and $[\mathrm{H}]$ due to the different deactivation schemes, overall rate constants, and branching ratios.

\section{Data and method}

\subsection{Satellite measurements}

\subsubsection{ENVISAT/SCIAMACHY}

The SCIAMACHY instrument (Bovensmann et al., 1999) was an eight-channel spectrometer on board ENVISAT, providing atmospheric $\mathrm{OH}$ airglow emission measurements between $\sim 220$ and $\sim 2380 \mathrm{~nm}$. ENVISAT was launched into a polar and sun-synchronous orbit and crossed the Equator at $\sim 10: 00$ and $\sim 22: 00$ LT. The ENVISAT mission started in March 2002 and SCIAMACHY was nearly continuously operating until the end of the mission in April 2012, caused by a spacecraft failure. The SCIAMACHY instrument performed measurements in different observations modes, including night-time $(\sim 22: 00 \mathrm{LT})$ limb scans over the tangent altitude range $\sim 75-150 \mathrm{~km}$. These measurements are only available throughout the year at latitudes between the Equator and $30^{\circ} \mathrm{N}$.

In this paper, we used SCIAMACHY level $1 \mathrm{~b}$ data v7.04 to retrieve $\mathrm{OH}$ airglow volume emission rates (VERs) of the $\mathrm{OH}(3-1)$ and $\mathrm{OH}(6-2)$ bands in the wavelength ranges of $1515-1546$ and $837.5-848.0 \mathrm{~nm}$, respectively. The retrieval approach applied here is very similar to the one described in von Savigny et al. (2012). The retrieval does not cover the complete spectra of the $\mathrm{OH}(3-1)$ and $\mathrm{OH}(6-2)$ bands, and consequently a "correction factor" of 2.48 for the $\mathrm{OH}(3-1)$ VER and 2.54 for the OH(6-2) VER was applied to account for the entire band emissions at mesopause temperature. The data set further includes corrections for misalignments and other measurement errors (Gottwald et al., 2007). Investigations performed by Bramstedt et al. (2012) showed a drift of the SCIAMACHY tangent height of less than $20 \mathrm{~m}_{\text {year }}{ }^{-1}$, which is negligible for our study.

The uncertainties of the OH(3-1) VER and $\mathrm{OH}(6-2)$ VER retrievals from SCIAMACHY limb observations correspond to the propagated uncertainties of the observed limb emission rate (LER) profiles. The profiles are estimated from the LER values in the tangent height range between 110 and $150 \mathrm{~km}$, where the actual atmospheric emissions should be zero. The VER uncertainties are first determined for daily and zonally averaged data. The uncertainties used in this analysis correspond to the mean uncertainties averaged over all days with co-located SCIAMACHY and SABER observations.

\subsubsection{TIMED/SABER}

The SABER instrument (Russell et al., 1999) on board the TIMED satellite has been nearly continuously operating since January 2002, collecting over $98 \%$ of all possible data. The instrument scans the atmosphere from the surface up to altitudes of $\sim 400 \mathrm{~km}$ while providing a vertical resolution of about $2 \mathrm{~km}$ throughout the entire height interval. Due to the geometry of the satellite orbit and the regular yaw manoeu- 
vres every $\sim 60-65$ days, SABER only provides complete coverage of the latitude range between $\sim 55^{\circ} \mathrm{S}$ and $\sim 55^{\circ} \mathrm{N}$. The SABER instrument measures the $\mathrm{OH}$ VERs at $\sim 2.0$ and at $\sim 1.6 \mu \mathrm{m}$, which approximately correspond to the transitions of $\mathrm{OH}(9-7)+\mathrm{OH}(8-6)$ and $\mathrm{OH}(5-3)+\mathrm{OH}(4-2)$, respectively. The contribution of $\mathrm{OH}(7-5)$ to the $\mathrm{OH}$ VER at $2.0 \mu \mathrm{m}$ and of $\mathrm{OH}(3-1)$ to the OH VER at $1.6 \mu \mathrm{m}$ is only about a few percent (Xu et al., 2012; Mlynczak et al., 2013a) and is neglected in this paper.

In this study, we used the SABER Level $2 \mathrm{~A}$ data v2.0 of the "unfiltered" OH VERs at $2.0 \mu \mathrm{m}$ and at $1.6 \mu \mathrm{m}$, the air temperature and pressure, and the volume mixing ratios (VMRs) of $\mathrm{O}_{3}$ (derived at $9.6 \mu \mathrm{m}$ ). There are also SABER $\mathrm{O}_{3}$ measurements at $1.27 \mu \mathrm{m}$, but these observations are not available during the night. New night-time VMRs of $\mathrm{O}\left({ }^{3} \mathrm{P}\right)$ and $\mathrm{H}$ (Mlynczak et al., 2018) were used for comparison with the results derived from our model. The "unfiltered" factor applied to the $\mathrm{OH}$ VER adjusts the originally measured $\mathrm{OH}$ VER from the SABER instrument to the total VER emitted by $\mathrm{OH}$ in the corresponding vibrational bands, while considering the shape, width, and transmission of the SABER broadband filters (Mlynczak et al., 2005). Outliers were excluded by screening the data as suggested by Mlynczak et al. (2013a). The SABER data used here were further restricted to observations between 21:00 and 23:00 LT to approximately match the SCIAMACHY measurement time at $\sim$ 22:00 LT. In order to be consistent with the naming of the SCIAMACHY OH airglow observations, the SABER $\mathrm{OH}$ airglow at $2.0 \mu \mathrm{m}$ and at $1.6 \mu \mathrm{m}$ is referred to as $\mathrm{OH}(9$ 7) $+\mathrm{OH}(8-6)$ and as $\mathrm{OH}(5-3)+\mathrm{OH}(4-2)$ throughout the paper.

The total uncertainty of SABER OH airglow data used here is comprised of three different error sources. Since we used climatology of the measurements (see Sect. 2.2), there are sufficient samples that the random noise component of the total uncertainty is essentially zero. The remaining two major terms are the absolute calibration error $(<5 \%)$ and the "unfiltered" factor error $(<3 \%)$. Assuming a root sum square propagation of the individual uncertainties, this results in a total uncertainty of about $6 \%$ for all data points presented in this study.

\subsection{Method}

In order to minimize uncertainties between SABER and SCIAMACHY due to different measurement characteristics, we focused on the latitude range from 0 to $10^{\circ} \mathrm{N}$, which was covered by both instruments throughout the entire year. A broader latitude band is not recommended because SABER and SCIAMACHY do not uniformly cover the same latitudes, leading to disagreements between the real latitude of the observations and the nominal latitude of the interval. The accepted profiles of both instruments within the chosen latitude interval were averaged to zonal-mean nightly mean values. All of these zonal-mean nightly means from January 2003 to December 2011 were used to calculate a cli- matology, only including days on which both SCIAMACHY and SABER data are available.

The approach to derive $\left[\mathrm{O}\left({ }^{3} \mathrm{P}\right)\right]$ and $[\mathrm{H}]$ applied here was developed by Good (1976) and is described in detail in Mlynczak et al. (2013a). Thus, we only give a brief summary here. The measured SABER OH(9-7)+OH(8-6) VER (photons $\mathrm{cm}^{-3} \mathrm{~s}^{-1}$ ) is given by Eq. (1):

$$
\begin{aligned}
& \mathrm{OH}(9-7)+\mathrm{OH}(8-6) \mathrm{VER}= \\
& k_{1}[\mathrm{H}]\left[\mathrm{O}_{3}\right] G\left(f_{v}, A_{\mathrm{vv}^{\prime}}, C_{\mathrm{vv}^{\prime}}\right),
\end{aligned}
$$

where $k_{1}$ is the rate constant of the chemical reaction $\mathrm{H}+\mathrm{O}_{3}$, representing direct production. The function $G$ (Eq. 2) comprises all relevant production and loss processes of the $\mathrm{OH}(9-$ 7) VER and OH(8-6) VER:

$$
\begin{aligned}
G & =\frac{f_{9}}{A_{9}+C_{9}} A_{97}+\frac{f_{8}}{A_{8}+C_{8}} A_{86} \\
& +\frac{f_{9}}{A_{9}+C_{9}} \frac{A_{98}+C_{98}}{A_{8}+C_{8}} A_{86} .
\end{aligned}
$$

The subscripts $v$ and $v^{\prime}\left(v^{\prime}<v\right)$ are the vibrational states of $\mathrm{OH}$ before and after the corresponding process. The term $f_{v}$ is the nascent distribution and describes the production efficiency of $\mathrm{OH}(v)$ via the reaction $\mathrm{H}+\mathrm{O}_{3}$. Total radiative loss due to spontaneous emissions is considered by the Einstein coefficients $A_{v}\left(\mathrm{~s}^{-1}\right)$, which are the inverse radiative lifetimes of $\mathrm{OH}(v)$. The total loss rate $C_{v}\left(\mathrm{~s}^{-1}\right)$ is the sum of loss due to collisions with the air compounds $\mathrm{N}_{2}, \mathrm{O}_{2}$, and $\mathrm{O}\left({ }^{3} \mathrm{P}\right)$, including chemical reactions and physical quenching. The terms $A_{v v^{\prime}}$ and $C_{v v^{\prime}}$ represent the specific state-to-state transitions.

In the second step, chemical equilibrium of $\mathrm{O}_{3}$ during the night is assumed as follows:

$k_{1}[\mathrm{H}]\left[\mathrm{O}_{3}\right]+k_{2}\left[\mathrm{O}\left({ }^{3} \mathrm{P}\right)\right]\left[\mathrm{O}_{3}\right]=k_{3}\left[\mathrm{O}\left({ }^{3} \mathrm{P}\right)\right]\left[\mathrm{O}_{2}\right][M]$,

meaning that $\mathrm{O}_{3}$ loss due to $\mathrm{H}$ and $\mathrm{O}\left({ }^{3} \mathrm{P}\right)$ (left side) is balanced by $\mathrm{O}_{3}$ formation via the three-body reaction $\mathrm{O}\left({ }^{3} \mathrm{P}\right)+\mathrm{O}_{2}+M$ (right side). Here, $k_{2}$ and $k_{3}$ are the corresponding rate constants of $\mathrm{O}\left({ }^{3} \mathrm{P}\right)+\mathrm{O}_{3}$ and $\mathrm{O}\left({ }^{3} \mathrm{P}\right)+\mathrm{O}_{2}+M$, respectively, while $M$ is an air molecule and $[M]$ is the total number density of the air.

Finally, rewriting Eq. (1) enables the derivation of $[\mathrm{H}]$, while $\left[\mathrm{O}\left({ }^{3} \mathrm{P}\right)\right]$ is calculated by substituting Eq. (3) in Eq. (1) and rewriting the resulting term as follows:

$$
\begin{aligned}
& {[\mathrm{H}]=\frac{\mathrm{OH}(9-7)+\mathrm{OH}(8-6) \mathrm{VER}}{G k_{1}\left[\mathrm{O}_{3}\right]},} \\
& {\left[\mathrm{O}\left({ }^{3} \mathrm{P}\right)\right]=\frac{\mathrm{OH}(9-7)+\mathrm{OH}(8-6) \mathrm{VER}}{G\left(k_{3}\left[\mathrm{O}_{2}\right][M]-k_{2}\left[\mathrm{O}_{3}\right]\right)} .}
\end{aligned}
$$

Air temperature and air pressure from SABER were used to calculate $[M],\left[\mathrm{O}_{2}\right]$ (VMR of 0.21$)$, and $\left[\mathrm{N}_{2}\right](\mathrm{VMR}$ of 0.78 ) via the ideal gas law, and $[M]$ was then used to convert $\mathrm{SABER}_{3}$ VMR into $\left[\mathrm{O}_{3}\right]$. The chemical reaction rates 
and physical quenching processes involved are described in Sect. 2.3. The values of $\left[\mathrm{O}\left({ }^{3} \mathrm{P}\right)\right]$ and $[\mathrm{H}]$ were individually derived for each altitude. Finally, the obtained vertical profiles of $\left[\mathrm{O}\left({ }^{3} \mathrm{P}\right)\right]$ and $[\mathrm{H}]$ were used to initialize the $\mathrm{OH}$ airglow model (see Sect. 2.3).

It is apparent from Eqs. (4a) and (4b) that any changes applied to the input parameters $\left(G, \mathrm{O}_{2}, \mathrm{O}_{3}, M, k_{1}, k_{2}, k_{3}\right)$ are balanced by the derived values of $\left[\mathrm{O}\left({ }^{3} \mathrm{P}\right)\right]$ and $[\mathrm{H}]$, without assuming any a priori information of $\left[\mathrm{O}\left({ }^{3} \mathrm{P}\right)\right]$ and $[\mathrm{H}]$. In contrast, the $\mathrm{OH}(9-7)+\mathrm{OH}(8-6)$ VER is not affected by the input parameters and therefore identical in every model run. However, the goal of this paper is to develop a model which does not only fit $\mathrm{OH}(9-7)+\mathrm{OH}(8-6)$ VER observations but also reproduces the three other airglow measurements: the $\mathrm{OH}(6-2) \mathrm{VER}, \mathrm{OH}(5-3)+\mathrm{OH}(4-2) \mathrm{VER}$, and $\mathrm{OH}(3-1)$ VER. We have to further point out that the relation between $\left[\mathrm{O}\left({ }^{3} \mathrm{P}\right)\right]$ and $\mathrm{OH}(9-7)+\mathrm{OH}(8-6)$ VER is not linear since the function $G$ also depends on $\left[\mathrm{O}\left({ }^{3} \mathrm{P}\right)\right]$, as represented by the terms $C_{v}$ and $C_{v v^{\prime}}$. In fact, Eq. (4b) is a quadratic expression with respect to $\left[\mathrm{O}\left({ }^{3} \mathrm{P}\right)\right]$ but is treated here as a linear expression, making no substantial differences for small $\left[\mathrm{O}\left({ }^{3} \mathrm{P}\right)\right]$. Nevertheless, this issue is addressed in detail in Sect. 3.4.

\subsection{The $\mathrm{OH}$ airglow base model}

The model used in this study is based on the atmospheric chemistry box model Module Efficiently Calculating the Chemistry of the Atmosphere/Chemistry As A Box model Application (MECCA/CAABA-3.72f; Sander et al., 2011). The box model calculates the temporal evolution of chemical species inside a single air parcel of a certain pressure and temperature, making the model well suited for sensitivity studies. The CAABA/MECCA standard model was extended by several chemical reactions and physical quenching processes involving $\mathrm{OH}(v)$ which are described in this section. The model was run until it reaches steady state, defined by the agreement between the measured and modelled $\mathrm{OH}(9-7)+\mathrm{OH}(8-6)$ VER.

The $\mathrm{OH}$ airglow model described in this section is referred to as the "base model" because it is the starting point of our model studies. But we have to point out that there is no such a thing as a commonly accepted $\mathrm{OH}$ airglow base model in the literature. The base model takes into account all major formation and loss processes of $\mathrm{OH}(v)$ (Table 1) which are commonly used in other models in the literature and are assumed not to be seriously in error. The model comprises the production of $\mathrm{OH}(v)$ via the chemical reaction $\mathrm{H}+\mathrm{O}_{3}$ as well as the deactivation due to spontaneous emission and the removal of physical quenching and chemical reactions with $\mathrm{N}_{2}$, $\mathrm{O}_{2}$, and $\mathrm{O}\left({ }^{3} \mathrm{P}\right)$.

The chemical reactions $\mathrm{H}+\mathrm{O}_{3}, \quad \mathrm{O}\left({ }^{3} \mathrm{P}\right)+\mathrm{O}_{3}$, and $\mathrm{O}\left({ }^{3} \mathrm{P}\right)+\mathrm{O}_{2}+M$ were already included in the CAABA/MECCA standard model and their corresponding rates were taken from the latest Jet Propulsion Laboratory (JPL) report 18 (Burkholder et al., 2015). The reaction
$\mathrm{H}+\mathrm{O}_{3}$ can populate $\mathrm{OH}(v)$ at all vibrational levels $v \leq 9$ and the nascent distribution of $\mathrm{OH}(v)$ was taken from AdlerGolden (1997). The spontaneous emissions are given by the Einstein coefficients at $200 \mathrm{~K}$ (Xu et al., 2012). Deactivation of $\mathrm{OH}(v)$ by $\mathrm{N}_{2}$ is assumed to occur via single-quantum quenching. The rates at room temperature for $\mathrm{OH}(v \leq 8)$ and for $\mathrm{OH}(v=9)$ were taken from Adler-Golden (1997) and Kalogerakis et al. (2011), respectively.

Quenching of $\mathrm{OH}(v)$ by $\mathrm{O}_{2}$ is based on the values reported by Adler-Golden (1997, their Table 3) which are comprised of a combination of multi-quantum and singlequantum quenching. However, Adler-Golden (1997) applied a factor of $\sim 1.5$ to account for mesopause temperature based on comparisons between laboratory measurements at room temperature of $\mathrm{OH}(v=8)+\mathrm{O}_{2}$ and the corresponding rate inferred from $\mathrm{OH}(8-3)$ rocket observations in the mesopause region. But later experiments reported by Lacousiere et al. (2003) and calculations by Caridade et al. (2002) suggest smaller values. The latter study further indicates that the temperature dependence decreases for lower vibrational levels and becomes negligible for $\mathrm{OH}(v \leq 4)$. Consequently, the rates presented in Adler-Golden (1997) were scaled to room temperature measurements $(v=1-6$, Dodd et al., 1991; $v=7$, Knutsen et al., 1996; $v=8$, Dyer et al., 1997; $v=9$, Kalogerakis et al., 2011), and afterwards a factor of 1.1 for $\mathrm{OH}(v \geq 6)$ and 1.05 for $\mathrm{OH}(v=5)$ was applied.

The removal of $\mathrm{OH}(v)$ via collisions with $\mathrm{O}\left({ }^{3} \mathrm{P}\right)$ is included by using a combination of multi-quantum quenching (Caridade et al., 2013, their Table 1) and chemical reactions (Varandas, 2004). The rates were obtained from quasiclassical trajectory calculations at $210 \mathrm{~K}$, approximately matching mesopause temperature.

As described in the previous section, the $\mathrm{OH}$ airglow model is adjusted to fit the $\mathrm{OH}(9-7)+\mathrm{OH}(8-6)$ VER, $\mathrm{OH}(6-$ 2) VER, $\mathrm{OH}(5-3)+\mathrm{OH}(4-2)$ VER, and $\mathrm{OH}(3-1)$ VER. Thus, the model cannot provide information about $\mathrm{OH}(v \leq 2)$. It further treats $\mathrm{OH}(v=9)$ and $\mathrm{OH}(v=8)$, as well as $\mathrm{OH}(v=$ 5) and $\mathrm{OH}(v=4)$ as a single level, and the corresponding deactivation channels presented in Tables 2 and 3 should be viewed more critically.

\section{Results and discussions}

Figure 1 displays vertical profiles of the (a) $\mathrm{OH}(6-2)$ VER, (b) $\mathrm{OH}(5-3)+\mathrm{OH}(4-2) \mathrm{VER}$, and (c) $\mathrm{OH}(3-1) \mathrm{VER}$, comparing the observations (black squares) with the corresponding base model output (red line). The model results of the $\mathrm{OH}(6-2)$ VER and $\mathrm{OH}(3-1)$ VER are a $4 \mathrm{~km}$ running average in order to take the averaging kernels of SCIAMACHY measurements into account. The base model approximately matches the general shape of the measured profiles but overestimates the three $\mathrm{OH}$ airglow measurements at the altitude of the maximum VER. A closer look at the relative differences shows that the ratio model/observation at the altitude 
Table 1. Physical processes and chemical reactions included in the base model.

\begin{tabular}{|c|c|c|c|}
\hline Process & & Rate or scheme & Reference \\
\hline \multirow[t]{2}{*}{$\mathrm{H}+\mathrm{O}_{3} \rightarrow \mathrm{OH}(v)+\mathrm{O}_{2}$} & (R1) & $k_{1}=1.4 \times 10^{-10} \mathrm{e}^{(-470 / T)}$ & Burkholder et al. (2015), \\
\hline & & $k_{1}(\nu)=k_{1} f_{1}(\nu)^{*}$ & Alder-Golden (1997, Table 1) \\
\hline $\mathrm{O}\left({ }^{3} \mathrm{P}\right)+\mathrm{O}_{3} \rightarrow \mathrm{O}_{2}+\mathrm{O}_{2}$ & (R2) & $k_{2}=8 \times 10^{-12} e^{(-2060 / T)}$ & Burkholder et al. (2015) \\
\hline $\mathrm{O}\left({ }^{3} \mathrm{P}\right)+\mathrm{O}_{2}+M \rightarrow \mathrm{O}_{3}+M$ & (R3) & $k_{3}=6 \times 10^{-34}(300 / T)^{2.4}$ & Burkholder et al. (2015) \\
\hline $\mathrm{OH}(v) \rightarrow \mathrm{OH}\left(v^{\prime}\right)+h v$ & (R4) & variable rates & Xu et al. (2012, Table A1) \\
\hline $\mathrm{OH}(v)+\mathrm{N}_{2} \rightarrow \mathrm{OH}\left(v^{\prime}\right)+\mathrm{N}_{2}$ & (R5) & $v^{\prime}=v-1$ & $\begin{array}{l}\text { Adler-Golden (1997, Table 1), } \\
\text { Kalogerakis et al. (2011) }\end{array}$ \\
\hline $\mathrm{OH}(v)+\mathrm{O}_{2} \rightarrow \mathrm{OH}\left(v^{\prime}\right)+\mathrm{O}_{2}$ & (R6) & $v^{\prime}<v$ & $\begin{array}{l}\text { Adler-Golden (1997, Table } 3) \text {; } \\
\text { see text for more information }\end{array}$ \\
\hline $\mathrm{OH}(v)+\mathrm{O}\left({ }^{3} \mathrm{P}\right) \rightarrow \mathrm{H}+\mathrm{O}_{2}$ & (R7a) & variable rates & Varandas (2004, Table 3, M I) \\
\hline $\mathrm{OH}(v)+\mathrm{O}\left({ }^{3} \mathrm{P}\right) \rightarrow \mathrm{OH}\left(v^{\prime}\right)+\mathrm{O}\left({ }^{3} \mathrm{P}\right)$ & (R7b) & $v^{\prime}<v$ & Caridade et al. (2013, Table 1) \\
\hline
\end{tabular}

Rate constants are given in cubic centimetres per second $\left(\mathrm{cm}^{3} \mathrm{~s}^{-1}\right) .{ }^{*} f_{1}(5,6,7,8,9)=0.01,0.03,0.15,0.34,0.47$.

Table 2. Empirically determined branching ratios of $\mathrm{OH}(v)+\mathrm{O}_{2} \rightarrow \mathrm{OH}\left(v^{\prime}\right)+\mathrm{O}_{2}$ of the $\mathrm{O}_{2}$ best-fit model based on $\mathrm{OH}(6-2)$ VER, OH(5-3)+OH(4-2) VER, and $\mathrm{OH}(3-1)$ VER observations.

\begin{tabular}{lllllrrr}
\hline$v / v^{\prime}$ & 8 & 7 & 6 & 5 & 4 & 3 & $\leq 2$ \\
\hline 9 & 0 & 0 & 0 & 0 & 1 & 0 & 0 \\
8 & & 0 & 0 & 0 & 0.3 & 0.7 & 0 \\
7 & & & 0 & 0 & 0 & 0.1 & 0.9 \\
6 & & & & 0 & 0 & 0 & 1 \\
5 & & & & & 0 & 0 & 1 \\
4 & & & & & & 0 & 1 \\
3 & & & & & & & 1 \\
\hline
\end{tabular}

of the maximum VER is about 2.0, 1.2, and 1.3 for $\mathrm{OH}(6-2)$, $\mathrm{OH}(5-3)+\mathrm{OH}(4-2)$, and $\mathrm{OH}(3-1)$, respectively. Furthermore, these ratios increase with decreasing altitude, indicating that the overestimation of the base model might be associated with $\mathrm{O}_{2}$ quenching.

The differences between the base model and observations are quite substantial in the case of the $\mathrm{OH}(6-2)$ VER. This implies a general problem in the rates or schemes included in the base model, requiring a detailed error analysis. The focus was set on potential error sources of the OH(6-2) VER because the relative differences between model and measurements are largest compared to the other two $\mathrm{OH}$ transitions, and secondly because changes of $\mathrm{OH}(v=6)$ will affect the lower vibrational levels, but not vice versa.

\subsection{Potential error sources of the OH(6-2) VER in the base model}

Based on the results presented in Fig. 1, the potential error source has to have an effect on the entire height interval and must have a stronger impact on $\mathrm{OH}(6-2)$ compared to the other two $\mathrm{OH}$ transitions. We further focus on quantities with large uncertainties. For the latter reason, temperature is ex- cluded as a possible source because in order to account for a reduction of the $\mathrm{OH}(6-2)$ VER by a factor of 2, temperature must be increased by more than $20 \mathrm{~K}$ (not shown here). Such a large error is very unlikely considering that a zonal-mean climatology (2003-2011) is used here.

Since the overestimation of the base model is especially large for the OH(6-2) VER, an impact of the Einstein coefficient of the corresponding transition must be considered. Regarding this aspect, we have to point out that studies based on the HITRAN 2004 data set should be viewed more critically because of erroneous $\mathrm{OH}$ transition probabilities. The Einstein coefficients used in this study were recently recalculated (Xu et al., 2012, their Table A1) and correspond to a temperature of $200 \mathrm{~K}$, which is very close to mesopause temperature. Furthermore, these Einstein coefficients are consistent with the values of the HITRAN 2008 data set (Rothman et al., 2009). However, there are several other data sets of Einstein coefficients found in literature that might lead to different results. We therefore carried out sensitivity runs, using the Einstein coefficients reported by Turnbull and Lowe (1989), Nelson et al. (1990), van der Loo and Groenenboom (2007), Xu et al. (2012; = base model), and Brooke et al. (2016). The corresponding results are presented in Fig. 2 and show considerably large differences in the case of the $\mathrm{OH}(6-2)$ VER, which are about a factor of 4 between the highest and lowest model output. In contrast, the individual simulations of $\mathrm{OH}(5-3)+\mathrm{OH}(4-2)$ VER and $\mathrm{OH}(3-1)$ VER are rather consistent and vary only by $\sim 10 \%$. These results emphasize that the choice of the Einstein coefficients is a potential error source for higher quanta transitions.

Regarding the credibility of the Einstein coefficients, it is generally assumed that the calculation will improve with time. However, this is not necessarily true at quanta changes $>2$ because it all depends on how good the representation of the Hamiltonian is for the $\mathrm{OH}$ molecule that is used to solve the Schrödinger equation. Multi-quanta transitions $>2$ quanta have small Einstein coefficients and are generally 

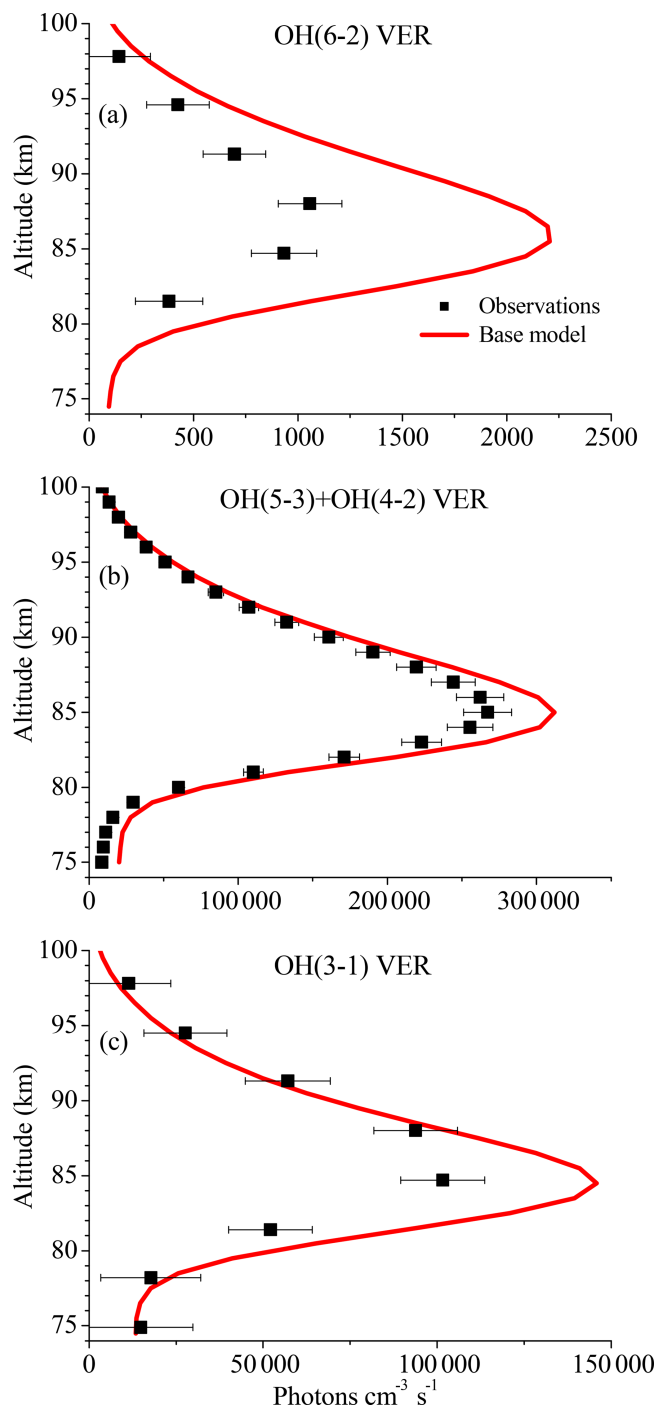

Figure 1. Comparison of vertical profiles of the volume emission rate (VER) of (a) $\mathrm{OH}(6-2)$, (b) $\mathrm{OH}(5-3)+\mathrm{OH}(4-2)$, and (c) $\mathrm{OH}(3-1)$ at $0-10^{\circ} \mathrm{N}$ between satellite observations and the base model output. The observations are the climatology of night-time mean zonal means from 2003 to 2011, based on co-location measurements of TIMED/SABER and ENVISAT/SCIAMACHY. Note the different scaling of the $x$ axis.

hard to model and calculate. The assessment of the Einstein coefficients requires a detailed analysis of the corresponding calculations, which is beyond the scope of this study. We therefore cannot exclude the values used in the base model as a potential error source, but we also think that our choice of the Einstein coefficients from Xu et al. (2012) is reasonable. Additionally, these values represent approximately the average model output of all five data sets considered here, while the model results based on Nelson et al. (1990) and van der Loo and Groenenboom (2007) represent the variability. Thus, we will not replace the Einstein coefficients from
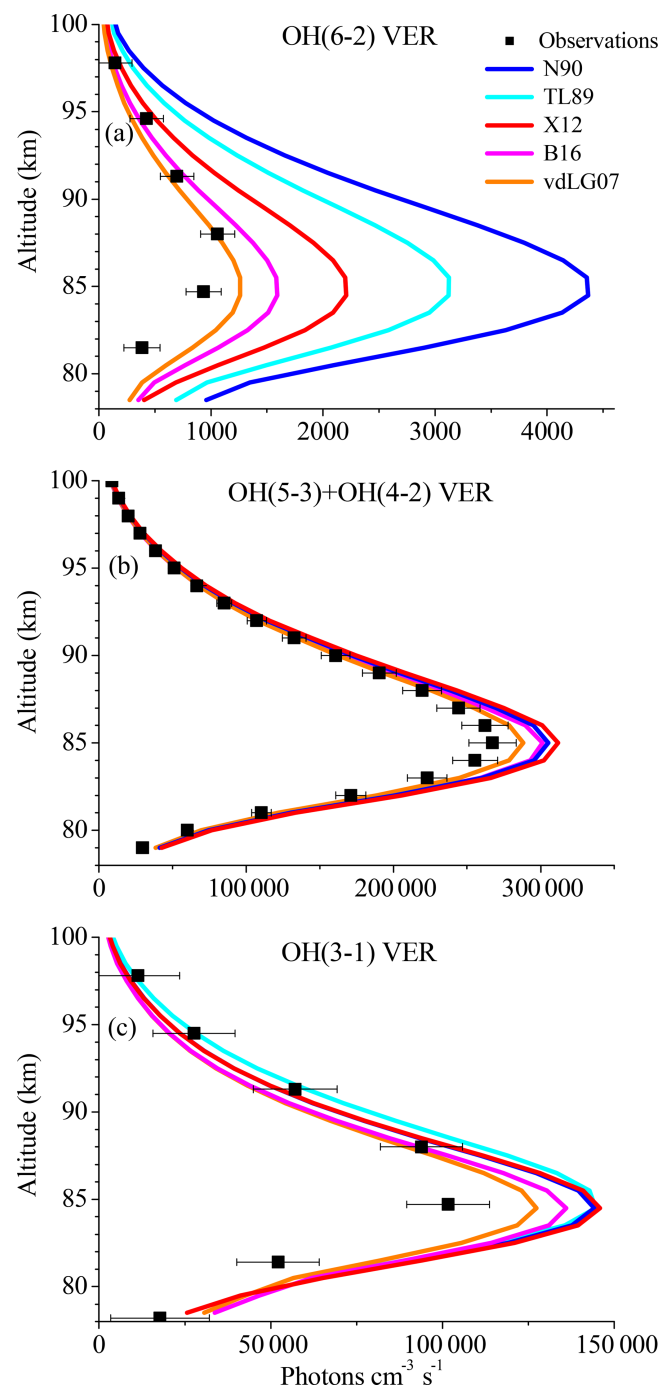

Figure 2. Same as Fig. 1 but for different sets of Einstein coefficients from literature, namely N90 (Nelson et al., 1990), TL89 (Turnbull and Lowe, 1989), X12 (=base model; Xu et al., 2012), B16 (Brooke et al., 2016), and vdLG07 (van der Loo and Groenenboom, 2007).

Xu et al. (2012) in our model, but keep in mind that they might be too large.

Furthermore, the best agreement between the observations and the model was obtained by applying the Einstein coefficients reported by van der Loo and Groenenboom (2007). But even in this case, the model still overestimates the observations of all $\mathrm{OH}$ transitions in the altitude region between $\sim 80$ and $\sim 86 \mathrm{~km}$. This pattern strongly supports the suggestion stated above that the rates and schemes associated with $\mathrm{OH}(v)+\mathrm{O}_{2}$ are incorrect.

The nascent distribution of the excited $\mathrm{OH}$ states of the chemical reaction $\mathrm{H}+\mathrm{O}_{3}$ was observed in several studies and all of them agree that $\mathrm{OH}(v)$ is primarily formed in the vibrational levels $v=8$ and $v=9$ (e.g. Charters et al., 1971; 
Streit and Johnston, 1976; Ohoyama et al., 1985; Klenerman and Smith, 1987). The values used in the base model, which are based on measurements reported by Charters et al. (1971), were taken from Adler-Golden (1997) and agree with values obtained by Klenerman and Smith (1987) and Streit and Johnston (1976). The values found by Ohoyama et al. (1985) show some differences, but according to Klenerman and Smith (1987) their results are fundamentally flawed. This also affects the nascent distribution used by Mlynczak and Solomon (1993), which is an average of Charters et al. (1971), Ohoyama et al. (1985), and Klenerman and Smith (1987).

Therefore, we think that our nascent distribution used here is likely not a serious error source. However, minor errors might be introduced by extrapolating the nascent distribution to lower vibrational levels as was done for the values used in our study (Adler-Golden, 1997). It is also possible that part of the nascent value of $\mathrm{OH}(v=6)$ is not due to direct production via $\mathrm{H}+\mathrm{O}_{3}$ but results from contributions of $\mathrm{OH}(v \geq 7)$. In order to test the potential impact of the $\mathrm{OH}(v=6)$ nascent value on the OH(6-2) VER, we assumed an extreme scenario by reducing the $\mathrm{OH}(v=6)$ nascent value from 0.03 to 0 . But the corresponding results of the OH(6-2) VER of the base model run (not shown here) are only about $15 \%$ lower compared to the values presented in Fig. 1. Further sensitivity runs also showed that an increase of the ratio $f_{9} / f_{8}$ is associated with a decrease of modelled OH(6-2) VER, but even the extreme case of $f_{9}=1$ and $f_{8}=0$ could not account for a factor of 2. Note that changes of the overall rate constant of $\mathrm{H}+\mathrm{O}_{3}$ affect all considered $\mathrm{OH}$ transitions in a similar way. Thus, we conclude that direct production of $\mathrm{OH}(v)$ is unlikely to be the reason for the overestimation of the $\mathrm{OH}(6-2)$ VER by the base model.

The physical removal of $\mathrm{OH}(v)$ by $\mathrm{N}_{2}$ is included as single-quantum relaxation which is supported by theoretical studies (Shalashilin et al., 1992; Adler-Golden, 1997). Assuming a sudden death scheme with the same overall deactivation rates resulted in a decrease of the simulated $\mathrm{OH}(6-$ 2) VER by less than $10 \%$ at the altitude of the maximum VER. The total deactivation rate for $\mathrm{OH}(v=9)$ used here is about 1.5 times higher than the one suggested by AdlerGolden (1997), but the difference between the corresponding model $\mathrm{OH}(6-2)$ VERs is negligible $(<1 \%)$. There are two studies reporting temperature dependence of $\mathrm{N}_{2}$ quenching (Shalashilin et al., 1992; Burtt and Sharma, 2008), both agreeing with measurements at room temperature. However, the calculations of the former study imply slower quenching rates at mesopause temperature compared to their respective values at room temperature, whereas the latter publication indicates the opposite behaviour, reporting a ratio between the rate at 200 and $300 \mathrm{~K}$ of approximately 1.7 for $\mathrm{OH}(v=8)$ and 1.3 for $\mathrm{OH}(v=9)$. These factors are generally supported by the results of López-Puertas et al. (2004), which applied an empirically determined factor of 1.4 to the rates of Adler-Golden (1997) to account for mesopause tem- perature. Since the temperature dependence is still uncertain, we tested both possibilities. We increased and decreased the overall $\mathrm{OH}(v)+\mathrm{N}_{2}$ quenching rates by a factor of 1.5 which led to higher or lower $\mathrm{OH}(6-2)$ VERs by about $5 \%$. Therefore, $\mathrm{N}_{2}$ is too inefficient as a $\mathrm{OH}(v)$ quenching partner to cause differences in the $\mathrm{OH}(6-2)$ VER of a factor of 2.

The overall rate and exact pathways of $\mathrm{OH}(v)+\mathrm{O}\left({ }^{3} \mathrm{P}\right)$ are also still not known well enough, but $\mathrm{O}\left({ }^{3} \mathrm{P}\right)$ has nearly no influence on $\mathrm{OH}(v)$ at altitudes below $85 \mathrm{~km}$. It therefore cannot be the only reason for the differences presented in Fig. 1. Consequently, deactivation by $\mathrm{O}_{2}$ is the only remaining candidate which has a crucial influence on $\mathrm{OH}(v)$ throughout the entire height interval. Therefore, we will first focus on $\mathrm{OH}(v)+\mathrm{O}_{2}$ (Sect. 3.2) before investigating a potential influence of $\mathrm{O}\left({ }^{3} \mathrm{P}\right)$ on $\mathrm{OH}(v)$ in Sect. 3.3.

\subsection{Deactivation of $\mathrm{OH}(v)$ by $\mathrm{O}_{2}$}

The overestimation of the $\mathrm{OH}(6-2)$ VER by the base model can be generally corrected either by slower rates of $\mathrm{OH}(v=$ $9,8,7)+\mathrm{O}_{2}$ or by a faster rate of $\mathrm{OH}(v=6)+\mathrm{O}_{2}$. The overall deactivation of $\mathrm{OH}(v=9)$ was measured by Chalamala and Copeland (1993), and they recommended a value of $2.1 \times$ $10^{-11} \mathrm{~cm}^{3} \mathrm{~s}^{-1}$. This result was later confirmed by Kalogerakis et al. (2011), reporting a rate of $2.2 \times 10^{-11} \mathrm{~cm}^{3} \mathrm{~s}^{-1}$. The rates for $\mathrm{OH}(v=8,7,6)+\mathrm{O}_{2}$ are each based on a single study only $(v=8$, Dyer et al., $1997 ; v=7$, Knutsen et al., 1996; $v=6$, Dodd et al., 1991). But, at least to our knowledge, there are no signs that the rates of $\mathrm{OH}(v=$ $9,8,7,6)+\mathrm{O}_{2}$ are fundamentally flawed. In order to test the impact of the individual rates on the OH(6-2) VER, we carried out sensitivity runs by varying the overall rates within their recommended $2 \sigma$ errors. Thus, we reduced the values of $\mathrm{OH}(v=9,8,7)+\mathrm{O}_{2}$ to $16 \times 10^{-12}, 7 \times 10^{-12} \mathrm{~cm}^{3} \mathrm{~s}^{-1}$, and $5 \times 10^{-12} \mathrm{~cm}^{3} \mathrm{~s}^{-1}$, respectively, while the rate of $\mathrm{OH}(v=$ $6)+\mathrm{O}_{2}$ was increased to $4.5 \times 10^{-12} \mathrm{~cm}^{3} \mathrm{~s}^{-1}$. But even under these favourable conditions, the base model output of the $\mathrm{OH}(6-2)$ VER only decreased by a factor of 1.5 , still not close to the required difference of a factor of 2 . Additionally, the assumed scenario is rather unlikely since the overall rates were obtained by independent studies.

The possibility of a systematic offset of $\mathrm{OH}(v \leq 6)+\mathrm{O}_{2}$ rates, which are based on the single study (Dodd et al., 1991), is also excluded because of the very good agreement of this $\mathrm{OH}(v=2)+\mathrm{O}_{2}$ rate with the value obtained by Rensberger et al. (1989). Furthermore, when we increased the $\mathrm{OH}(v \leq$ 6) $+\mathrm{O}_{2}$ rates by a factor of 3 , the base model approximately fits the $\mathrm{OH}(6-2)$ VER and $\mathrm{OH}(3-1)$ VER but underestimates the $\mathrm{OH}(5-3)+\mathrm{OH}(4-2)$ VER by more than $30 \%$. Temperature dependence also affects the $\mathrm{O}_{2}$ deactivation rates used here. But the factor to account for mesopause region temperature is suggested to be lower than 1.3 (Lacousiere et al., 2003; Cadidade et al., 2002), which has a weaker impact on the OH(6-2) VER than the scenarios considered above. 
Consequently, when applying the standard deactivation rates and schemes found in the literature, neither errors in the overall rates nor uncertainties in the temperature dependence can give a reasonable explanation of the overestimation of the OH(6-2) VER base model output shown in Fig. 1a. Since the overall rates were actually measured, while the deactivation schemes are solely based on theoretical considerations, it is more convincing that the potential error source lies within $\mathrm{OH}(v)+\mathrm{O}_{2}$ deactivation scheme rather than in the deactivation rates.

In order to considerably reduce the $\mathrm{OH}(6-2) \mathrm{VER}$, we assumed an extreme scenario and substituted the multiquantum relaxation $\left(\mathrm{OH}(v)+\mathrm{O}_{2} \rightarrow \mathrm{OH}\left(v^{\prime}<v\right)+\mathrm{O}_{2}\right)$ in the base model via a sudden death $\left(\mathrm{OH}(v)+\mathrm{O}_{2} \rightarrow \mathrm{OH}+\mathrm{O}_{2}\right)$ approach. This new model is referred to as " $\mathrm{O}_{2} \mathrm{SD}$ model" and the corresponding results are displayed in Fig. 3 as red lines, showing that the simulated OH(6-2) VER matches the observations within the error bars below $85 \mathrm{~km}$ and above $\sim 92 \mathrm{~km}$. The model still overestimates the measurements in the altitude region $\sim 90 \mathrm{~km}$, which might be related to $\mathrm{O}\left({ }^{3} \mathrm{P}\right)$ quenching (see Sect. 3.3). The $\mathrm{O}_{2} \mathrm{SD}$ model output for the other two $\mathrm{OH}$ transitions (Fig. 3b-c) is clearly too low, implying that $\mathrm{OH}(v)+\mathrm{O}_{2}$ quenching cannot occur via sudden death alone. We also conclude that the contribution of higher excited states $\mathrm{OH}(v \geq 7)$ to $\mathrm{OH}(v=6)$ must be negligible or even zero and these higher states are suggested to primarily populate lower vibrational levels $\mathrm{OH}(v \leq 5)$. Therefore, $\mathrm{OH}(v)+\mathrm{O}_{2}$ has to occur via multi-quantum quenching, because in the case of single-quantum deactivation the contribution of $\mathrm{OH}(v \geq 7)$ to $\mathrm{OH}(v=6)$ is considerably larger than zero.

According to Finlayson-Pitts and Kleindienst (1981), $\mathrm{OH}(v)$ might relax to $v^{\prime}=v-5$ while the excess energy is transferred to form $\mathrm{O}_{2}\left(b^{1} \Sigma\right)$. This vibration-to-electronic energy transfer was also mentioned by Anlauf et al. (1968) and is supported by the close energy match of the transition from $\mathrm{OH}(v=9)$ to $\mathrm{OH}(v=4)$, and from $\mathrm{O}_{2}\left(X^{3} \Sigma\right)$ to $\mathrm{O}_{2}\left(b^{1} \Sigma\right)$ of about 36.6 and $37.5 \mathrm{kcal} \mathrm{mol}^{-1}$, respectively. Although there is no experimental support of this deactivation pathway, this approach gives a reasonable explanation for the observed pattern in our study and $\mathrm{OH}(v)$ as a potential source of excited $\mathrm{O}_{2}$, as discussed in Howell et al. (1990) and Murtagh et al. (1990). However, evaluating whether the product is really $\mathrm{O}_{2}\left(b^{1} \Sigma\right)$ or another excited $\mathrm{O}_{2}$ state is beyond the scope of this study. Thus, we concluded that deactivation of $\mathrm{OH}(v)$ by $\mathrm{O}_{2}$ has to satisfy the following condition:

$\mathrm{OH}(v \geq 6)+\mathrm{O}_{2} \rightarrow \mathrm{OH}\left(v^{\prime} \leq 5\right)+\mathrm{O}_{2}$,

while we further assume that the pathway

$\mathrm{OH}(v \geq 6)+\mathrm{O}_{2} \rightarrow \mathrm{OH}\left(v^{\prime}=v-5\right)+\mathrm{O}_{2}$,

is the preferred deactivation channel.

In order to test whether Reaction (R9) could be the only pathway of Reaction (R8) we assumed multi-quantum relax-
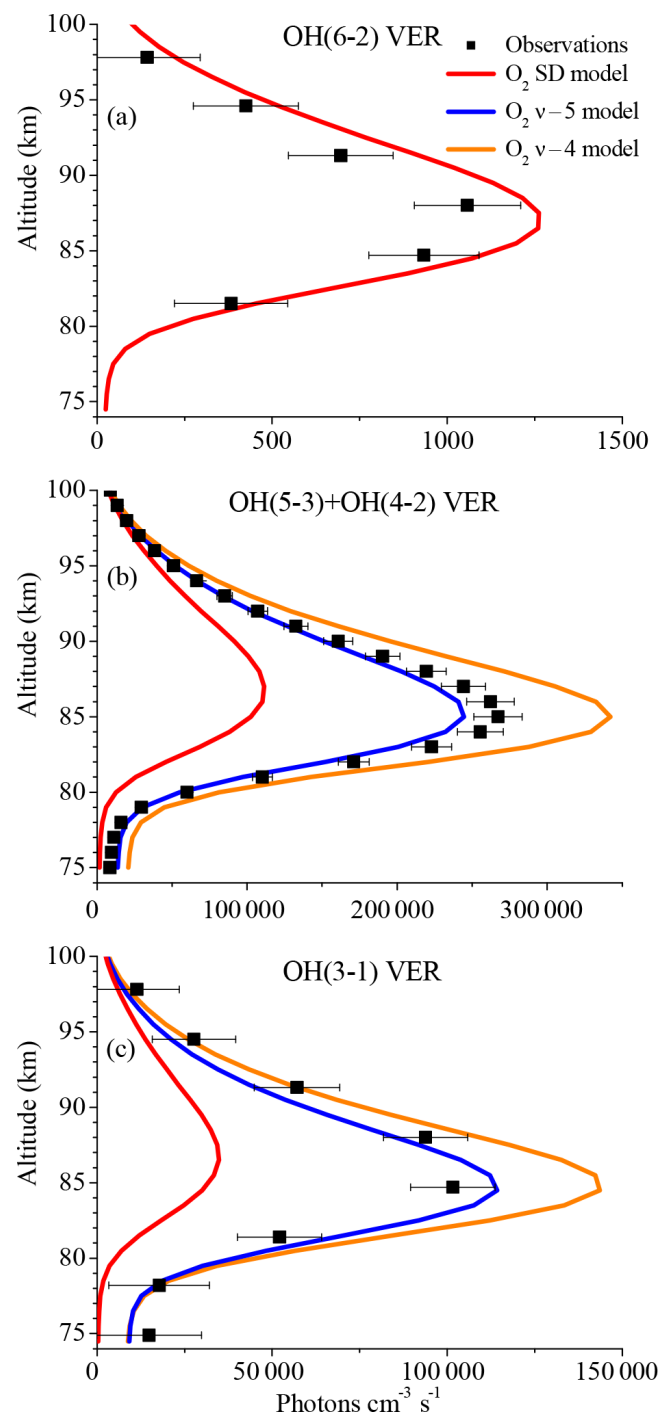

Figure 3. Same as Fig. 1 but for the $\mathrm{O}_{2}$ SD model, the $\mathrm{O}_{2} v-5$ model, and the $\mathrm{O}_{2} v-4$ model. Note that the results of these three models are identical in the case of the OH(6-2) VER.

ation via

$\mathrm{OH}(v)+\mathrm{O}_{2} \rightarrow \mathrm{OH}(v-5)+\mathrm{O}_{2}$

or $\mathrm{OH}(v)+\mathrm{O}_{2} \rightarrow \mathrm{OH}(v-4)+\mathrm{O}_{2}$.

If Reaction (R10a) is integrated in the model (Fig. 3bc, $\mathrm{O}_{2} v-5$ model), the corresponding model output at altitudes $<90 \mathrm{~km}$ is only about $10 \%$ below the observations of the $\mathrm{OH}(5-3)+\mathrm{OH}(4-2)$ VER and approximately matches the $\mathrm{OH}(3-1)$ VER measurements within the error bars. The underestimation of the $\mathrm{OH}(5-3)+\mathrm{OH}(4-2)$ VER measurements by the model could be attributed to minor errors of the $\mathrm{OH}(v)+\mathrm{O}_{2}$ overall rates in combination with a slightly different $\mathrm{OH}(v)$ branching of $\mathrm{H}+\mathrm{O}_{3}$. Therefore, we cannot completely rule out Reaction (R10a) as a possible solution, even if there are still some differences between the modelled 

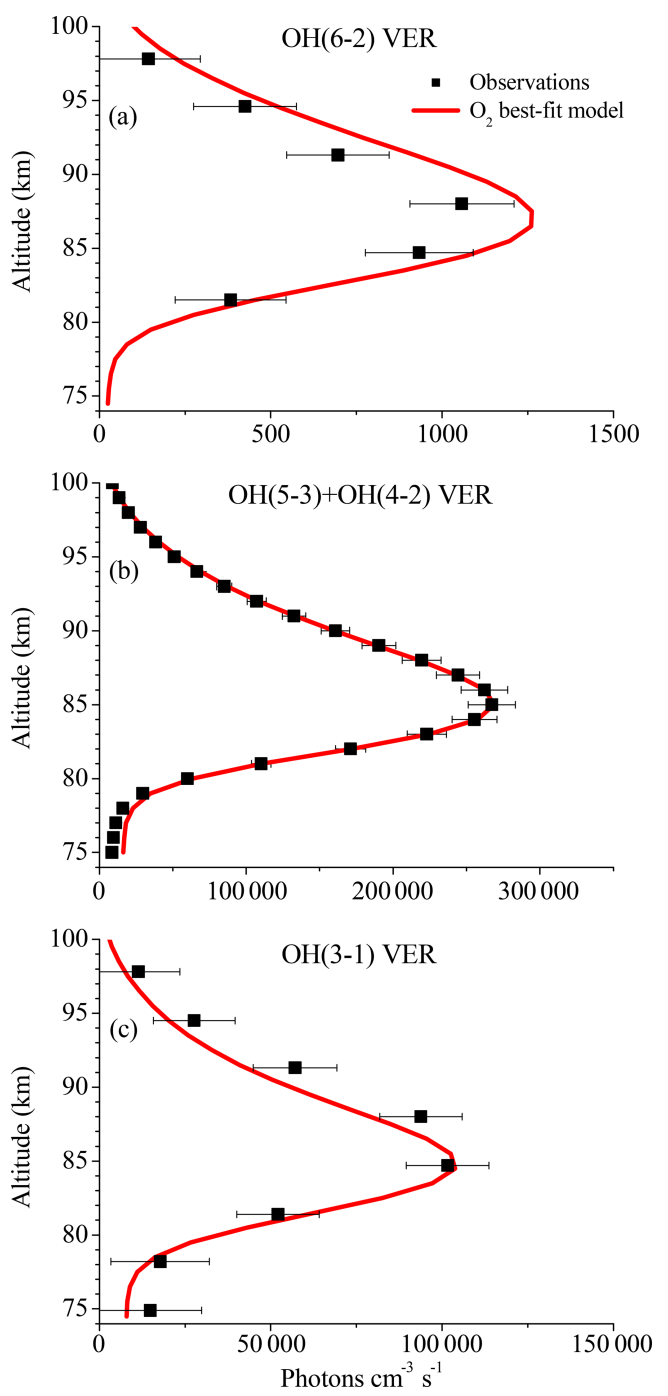

Figure 4. Same as Fig. 1 but for the $\mathrm{O}_{2}$ best-fit model. Note that Fig. 4a is identical to Fig. 3a but was plotted again for convenience.

and the observed OH VER. Replacing Reaction (R10a) with Reaction (R10b) in the model (Fig. 3b-c, $\mathrm{O}_{2} v-4$ model) results in an overestimation of the observations of $\mathrm{OH}(5-$ $3)+\mathrm{OH}(4-2)$ VER and $\mathrm{OH}(3-1)$ VER of about $20 \%$ to $30 \%$, and consequently this assumption is not further considered as a potential solution.

The results shown in Fig. 3 suggest that the $\mathrm{OH}$ airglow model is not able to reproduce the three $\mathrm{OH}$ airglow observations when sudden death or simplified multi-quantum schemes for $\mathrm{OH}(v)+\mathrm{O}_{2}$ are applied. But the $\mathrm{O}_{2} v-5$ model output is quite close to the measurements, suggesting that Reaction (R9) might be the dominating deactivation channel within a multi-quantum relaxation scheme in accordance with Reaction (R8). We therefore included these two conditions in the so-called " $\mathrm{O}_{2}$ best-fit model" and the results are displayed in Fig. 4. The corresponding branching ratios for the individual pathways are summarized in Table 2.
The simulated $\mathrm{OH}$ airglow fits well with the three $\mathrm{OH}$ airglow observations within the error bars below $85 \mathrm{~km}$. In the altitude region above $85 \mathrm{~km}$, it is seen that the model still overestimates the $\mathrm{OH}(6-2)$ VER while the $\mathrm{OH}(3-1)$ VER is indicated to be slightly underestimated. Furthermore, this pattern is not seen in the $\mathrm{OH}(5-3)+\mathrm{OH}(4-2)$ VER and therefore could be attributed to deviations due to the different satellite/instrument configurations between TIMED/SABER and ENVISAT/SCIAMACHY. But since this behaviour only occurs in the upper part of the vertical profiles and is not seen throughout the entire height interval, it is more likely related to $\mathrm{O}\left({ }^{3} \mathrm{P}\right)$ quenching.

\subsection{Deactivation of $\mathrm{OH}(v)$ by $\mathrm{O}\left({ }^{3} \mathrm{P}\right)$}

Only recently, Sharma et al. (2015) proposed a new pathway of $\mathrm{OH}(v)+\mathrm{O}\left({ }^{3} \mathrm{P}\right)$ by providing a direct link between higher and lower vibrational levels via

$\mathrm{OH}(v)+\mathrm{O}\left({ }^{3} \mathrm{P}\right) \rightarrow \mathrm{OH}\left(0 \leq v^{\prime} \leq v-5\right)+\mathrm{O}\left({ }^{1} \mathrm{D}\right)$,

with the vibrationally independent reaction constant $k_{11}=$ $2.3 \times 10^{-10} \mathrm{~cm}^{3} \mathrm{~s}^{-1}$. While the value of $k_{11}(v=9)$ is based on measurements (Kalogerakis et al., 2011; Thiebaud et al., 2010) and on calculations (Varandas, 2004), the values for $k_{11}(v=5,6,7,8)$ are only assumed to be identical to $k_{11}(v=$ 9) and should be viewed more critically.

We adapted Reaction (R11) in the " $\mathrm{O}_{2}$ best-fit $\mathrm{O}\left({ }^{3} \mathrm{P}\right)$ $v-5$ model" in such a way that the product is $\mathrm{OH}\left(v^{\prime}=\right.$ $v-5)+\mathrm{O}\left({ }^{1} \mathrm{D}\right)$ and the results obtained are displayed as blue lines in Fig. 5. Comparisons for the OH(6-2) VER in Fig. 5a show an underestimation of the model at altitudes $>85 \mathrm{~km}$. A sensitivity study was carried out that showed that the impact of $\mathrm{OH}(v=9,8,7)+\mathrm{O}\left({ }^{3} \mathrm{P}\right)$ on the $\mathrm{OH}(6-2)$ VER is negligible. This is reasonable because these three upper states only indirectly influence $\mathrm{OH}(6-2)$ via Reaction (R11). Consequently, our analysis suggests a lower value of $k_{11}(v=6)$ and the best agreement between the model output and the $\mathrm{OH}(6-2)$ VER observations was obtained for an overall rate of approximately $0.8 \times 10^{-10} \mathrm{~cm}^{3} \mathrm{~s}^{-1}$.

In the case of the OH(5-3)+OH(4-2) VER, presented in Fig. $5 \mathrm{~b}$, the new approach leads to a weak underestimation of the observations by the model in the altitude region above $85 \mathrm{~km}$, even if $\mathrm{OH}(v=9)+\mathrm{O}\left({ }^{3} \mathrm{P}\right)$ of Reaction (R11) solely populates $\mathrm{OH}(v=4)$. The model results are most sensitive to $k_{11}(v=5)$, and therefore this rate might be too fast. Considering our best-fit value obtained for $k_{11}(v=6)$, it is indicated that $k_{11}(v)$ decreases with decreasing vibrational level and this feature is discussed below in more detail. Thus, an upper limit of $k_{11}(v=5)<k_{11}(v=6)$ is recommended and the actual rate coefficient has to balance the direct contribution of $\mathrm{OH}(v=9)$ to $\mathrm{OH}(v=4)$ via Reaction (R11). Investigating another scenario of $k_{11}(v=5)$ being zero showed that the branching of $\mathrm{OH}(v=9)$ to $\mathrm{OH}(v=4)$ has to be at least about 0.6 , which corresponds to a rate of $\mathrm{a} \sim 1.4 \times 10^{-10} \mathrm{~cm}^{3} \mathrm{~s}^{-1}$. 
Table 3. Empirically determined branching ratios of $\mathrm{OH}(v)+\mathrm{O}\left({ }^{3} \mathrm{P}\right) \rightarrow \mathrm{OH}\left(v^{\prime}\right)+\mathrm{O}\left({ }^{1} \mathrm{D}\right)$ of the best-fit model based on the $\mathrm{OH}(6-2) \mathrm{VER}$, $\mathrm{OH}(5-3)+\mathrm{OH}(4-2) \mathrm{VER}$, and $\mathrm{OH}(3-1)$ VER observations.

\begin{tabular}{llll}
\hline Process & & Recommendation & Best-fit rate $\left(\mathrm{cm}^{3} \mathrm{~s}^{-1}\right)$ \\
\hline $\mathrm{OH}(9)+\mathrm{O}\left({ }^{3} \mathrm{P}\right) \rightarrow \mathrm{OH}(4)+\mathrm{O}\left({ }^{1} \mathrm{D}\right)$ & (R11a) & $k_{11}(9-4)>0.6 \times k_{11}(v=9)$ & $0.8 \times 2.30 \times 10^{-10}$ \\
$\mathrm{OH}(9)+\mathrm{O}\left({ }^{3} \mathrm{P}\right) \rightarrow \mathrm{OH}(3)+\mathrm{O}\left({ }^{1} \mathrm{D}\right)$ & (R11b) & Not negligible & $0.2 \times 2.30 \times 10^{-10}$ \\
$\mathrm{OH}(8)+\mathrm{O}\left({ }^{3} \mathrm{P}\right) \rightarrow \mathrm{OH}(3)+\mathrm{O}\left({ }^{1} \mathrm{D}\right)$ & $(\mathrm{R} 11 \mathrm{c})$ & $k_{11}(v=8)<k_{11}(v=9)$ & $1.0 \times 1.80 \times 10^{-10}$ \\
$\mathrm{OH}(7)+\mathrm{O}\left({ }^{3} \mathrm{P}\right) \rightarrow \mathrm{OH}(\leq 2)+\mathrm{O}\left({ }^{1} \mathrm{D}\right)$ & $(\mathrm{R} 11 \mathrm{~d})$ & $k_{11}(7-\leq 2)<k_{11}(v=8)$ & $1.25 \times 10^{-10}$ \\
$\mathrm{OH}(6)+\mathrm{O}\left({ }^{3} \mathrm{P}\right) \rightarrow \mathrm{OH}(\leq 1)+\mathrm{O}\left({ }^{1} \mathrm{D}\right)$ & $(\mathrm{R} 11 \mathrm{e})$ & $k_{11}(6-\leq 1)<k_{11}(v=7)$ & $0.80 \times 10^{-10}$ \\
$\mathrm{OH}(5)+\mathrm{O}\left({ }^{3} \mathrm{P}\right) \rightarrow \mathrm{OH}+\mathrm{O}\left({ }^{1} \mathrm{D}\right)$ & (R11f) & $k_{11}(v=5)<k_{11}(v=6)$ & $0.40 \times 10^{-10}$ \\
\hline
\end{tabular}
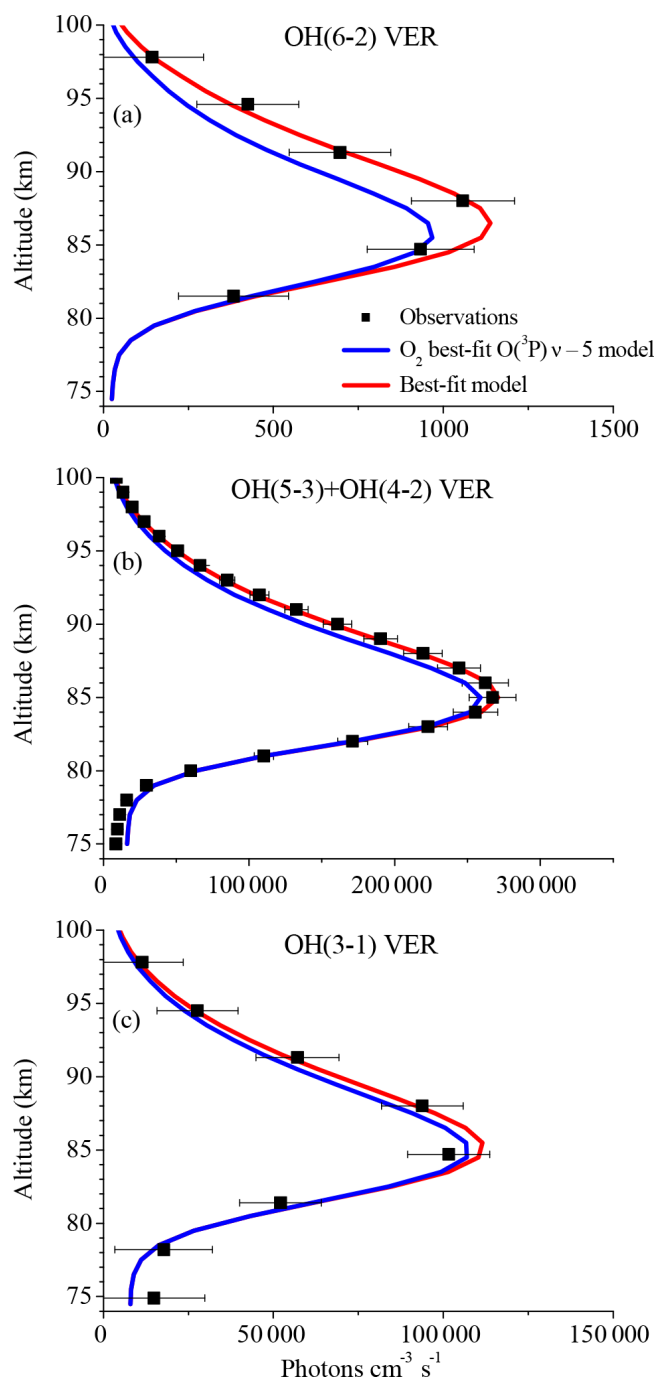

Figure 5. Same as Fig. 1 but for the $\mathrm{O}_{2}$ best-fit $\mathrm{O}\left({ }^{3} \mathrm{P}\right) v-5$ model and the best-fit model.

The assumption that $k_{11}(v)$ decreases at lower vibrational levels is supported by the overall rate of $\mathrm{OH}(v=7)+\mathrm{O}\left({ }^{3} \mathrm{P}\right) \rightarrow \mathrm{OH}\left(v^{\prime}\right)+\mathrm{O}\left({ }^{1} \mathrm{D}\right)$ at mesopause temperature, which is suggested to be on the order of $0.9-1.6 \times$
$10^{-10} \mathrm{~cm}^{3} \mathrm{~s}^{-1}$ (Thiebaud et al., 2010; Varandas, 2004). At least to our knowledge, the total rate of $\mathrm{OH}(v=$ $8)+\mathrm{O}\left({ }^{3} \mathrm{P}\right) \rightarrow \mathrm{OH}\left(v^{\prime}\right)+\mathrm{O}\left({ }^{1} \mathrm{D}\right)$ was not measured. Nevertheless, results reported by Mlynczak et al. (2018) and Panka et al. $(2017,2018)$ indicate that this rate might be slower than the value of $2.3 \times 10^{-10} \mathrm{~cm}^{3} \mathrm{~s}^{-1}$ suggested by Sharma et al. (2015). This is also in agreement with our findings here, because applying $2.3 \times 10^{-10} \mathrm{~cm}^{3} \mathrm{~s}^{-1}$ for $k_{11}(v=9,8)$ results in non-physical $\left[\mathrm{O}\left({ }^{3} \mathrm{P}\right)\right]$ values above $90 \mathrm{~km}$. The corresponding value of $\left[\mathrm{O}\left({ }^{3} \mathrm{P}\right)\right]$, e.g. at $95 \mathrm{~km}$, is about 1.25 times larger than SABER $\left[\mathrm{O}\left({ }^{3} \mathrm{P}\right)\right] 2013$ (Mlynczak et al., 2013a) which in turn is about 1.15 times larger than the upper limit of $\left[\mathrm{O}\left({ }^{3} \mathrm{P}\right)\right]$ (Mlynczak et al., 2013b, their Fig. 4). This results in a factor of $1.15 \times 1.25=1.44(=44 \%)$ above the upper limit and cannot be explained by the uncertainty of the $\left[\mathrm{O}\left({ }^{3} \mathrm{P}\right)\right]$ profile derived here $(40 \%$; see Sect. 3.4$)$. In order to obtain reasonable $\left[\mathrm{O}\left({ }^{3} \mathrm{P}\right)\right]$ values, it was necessary to lower the rate of $k_{11}(v=8)$ to $1.8 \times 10^{-10} \mathrm{~cm}^{3} \mathrm{~s}^{-1}$, and we therefore recommend $k_{11}(v=8) \leq 1.8 \times 10^{-10} \mathrm{~cm}^{3} \mathrm{~s}^{-1}$ as an upper limit to derive physically allowed $\left[\mathrm{O}\left({ }^{3} \mathrm{P}\right)\right]$ values.

It is seen in Fig. 5c that observations and $\mathrm{O}_{2}$ best-fit $\mathrm{O}\left({ }^{3} \mathrm{P}\right)$ $v-5$ model output of the $\mathrm{OH}(3-1)$ VER are in agreement within the corresponding measurement errors, but the model values seem to be slightly too low at heights $>85 \mathrm{~km}$. In this altitude region, simulated $\mathrm{OH}(3-1)$ VER is most influenced by $\mathrm{OH}(v=9,8)+\mathrm{O}\left({ }^{3} \mathrm{P}\right)$ of Reaction (R11) because both vibrational levels can directly populate $\mathrm{OH}(v=3)$. However, not much is known about the individual branching ratios of Reaction (R11) except that $\mathrm{OH}(v=9)+\mathrm{O}\left({ }^{3} \mathrm{P}\right) \rightarrow \mathrm{OH}(v=$ 3) $+\mathrm{O}\left({ }^{1} \mathrm{D}\right)$ is an important deactivation channel but not necessarily the dominating one, as described in Kalogerakis et al. (2016). These authors further suggested a rate of $2.3( \pm 1.0) \times 10^{-10} \mathrm{~cm}^{3} \mathrm{~s}^{-1}$ and noted that this rate might be slower due to the involvement of excited surfaces. This generally agrees with our results presented here because the $\mathrm{O}_{2}$ best-fit $\mathrm{O}\left({ }^{3} \mathrm{P}\right) v-5$ model only considers a contribution of $\mathrm{OH}(v=8)$ to $\mathrm{OH}(v=3)$ and the underestimation indicated in Fig. $5 \mathrm{c}$ could be attributed to the missing channel $\mathrm{OH}(v=9)+\mathrm{O}\left({ }^{3} \mathrm{P}\right) \rightarrow \mathrm{OH}(v=3)+\mathrm{O}\left({ }^{1} \mathrm{D}\right)$. The conclusions drawn from comparisons between three different airglow observations and our model studies with respect to $\mathrm{OH}(v)+\mathrm{O}\left({ }^{3} \mathrm{P}\right)$ quenching are summarized in Table 3. 
Finally, all of these findings presented in Tables 2 and 3 were adapted in the "best-fit model" (Fig. 5, red lines), resulting in an overall agreement between model output and measurements within the corresponding errors. Note that $k_{11}(v=7)$ used here is the average of the lower and upper limits derived from Thiebaud et al. (2010) and Varandas (2004) which is unlikely to be seriously in error. Furthermore, we have to point out that lowering $k_{11}(v=8)$ does only impact the $\left[\mathrm{O}\left({ }^{3} \mathrm{P}\right)\right]$ and $[\mathrm{H}]$ derived here but does not affect the general conclusions drawn in this section.

The empirically determined solution presented here implies that the contribution of $\mathrm{OH}(v=9)$ to $\mathrm{OH}(v=8)$ via quenching with $\mathrm{O}\left({ }^{3} \mathrm{P}\right)$ is close to zero (see Table 1 and this section). In contrast, the model described in Mlynczak et al. (2018) assumes single-quantum relaxation $(\mathrm{OH}(v=$ 9) $\left.+\mathrm{O}\left({ }^{3} \mathrm{P}\right) \rightarrow \mathrm{OH}(v=8)+\mathrm{O}\left({ }^{3} \mathrm{P}\right)\right)$ to get the global annual energy budget into near balance. But applying this approach in our $\mathrm{OH}$ model (same total rate of $3 \times 10^{-10} \mathrm{~cm}^{3} \mathrm{~s}^{-1}$ and varying the rates for $\left.\mathrm{OH}(v \leq 8)+\mathrm{O}\left({ }^{3} \mathrm{P}\right)\right)$ leads to a considerable overestimation of the $\mathrm{OH}(6-2)$ VER. Additionally, the shape of the simulated $\mathrm{OH}(5-3)+\mathrm{OH}(4-2)$ VER slightly mismatches the observed $\mathrm{OH}(5-3)+\mathrm{OH}(4-2)$ VER above $90 \mathrm{~km}$ (not shown here). Based on these sensitivity runs, we conclude that at least part of the $\mathrm{OH}(v=9)+\mathrm{O}\left({ }^{3} \mathrm{P}\right)$ channel has to be deactivated via multi-quantum quenching. This is supported by the results presented by Panka et al. (2017) which adjusted an $\mathrm{OH}$ airglow model to fit night-time $\mathrm{CO}_{2}\left(v_{3}\right)$ emissions at $4.3 \mu \mathrm{m}$. However, this study reported empirically determined rates for $\mathrm{OH}(5 \leq v \leq 8)+\mathrm{O}\left({ }^{3} \mathrm{P}\right)$ generally higher than the rates obtained in this work. But these differences might be attributed to their faster values of $\mathrm{OH}(v)+\mathrm{O}_{2}$ because they seem to have falsely assumed that the rates of Adler-Golden (1997) do not take mesopause temperature into account. Thus, we think that their rates of $\mathrm{OH}(v)+\mathrm{O}_{2}$ are too high by at least a factor of $\sim 1.5$. Since Panka et al. (2017) performed an empirical study, it is not possible to estimate how much this issue affects the rates of $\mathrm{OH}(5 \leq v \leq$ $8)+\mathrm{O}\left({ }^{3} \mathrm{P}\right)$. But we know from our work that higher rates of $\mathrm{OH}(v)+\mathrm{O}_{2}$ lead to higher values of the $\mathrm{OH}(6-2) \mathrm{VER}, \mathrm{OH}(5-$ 2) $+\mathrm{OH}(4-2)$ VER, and $\mathrm{OH}(3-1)$ VER, which can be generally balanced by higher rates of $\mathrm{OH}(5 \leq v \leq 8)+\mathrm{O}\left({ }^{3} \mathrm{P}\right)$. Considering our comparisons with these two studies, we think that the rates of $\mathrm{OH}(v)+\mathrm{O}\left({ }^{3} \mathrm{P}\right)$ should be investigated in more detail in future studies as this rate has a huge impact on derived values of $\left[\mathrm{O}\left({ }^{3} \mathrm{P}\right)\right]$ (Panka et al., 2018).

\subsection{Derived profiles of $\left[\mathrm{O}\left({ }^{3} \mathrm{P}\right)\right]$ and $[\mathrm{H}]$}

Figure 6 displays the vertical profiles of $\left[\mathrm{O}\left({ }^{3} \mathrm{P}\right)\right]$ and $[\mathrm{H}]$ obtained by the best-fit model in comparison with the results only derived from the SABER OH(9-7)+OH(8-6) VER (Mlynczak et al., 2018). The $\left[\mathrm{O}\left({ }^{3} \mathrm{P}\right)\right]$ profiles seen in Fig. 6a agree below $85 \mathrm{~km}$, but the best-fit model shows gradually larger values in the altitude region above. Between 85 and $95 \mathrm{~km}$ these larger values are caused by the different deac- tivation rates and schemes of $\mathrm{OH}(v)+\mathrm{O}\left({ }^{3} \mathrm{P}\right)$, agreeing with general pattern reported in Panka et al. (2018). We have to point out that other studies (e.g. von Savigny and Lednyts'kyy, 2013) observed a pronounced $\left[\mathrm{O}\left({ }^{3} \mathrm{P}\right)\right]$ maximum of about $8 \times 10^{11} \mathrm{~cm}^{-3}$ at $95 \mathrm{~km}$. The $\left[\mathrm{O}\left({ }^{3} \mathrm{P}\right)\right]$ derived here indeed shows similar values at $95 \mathrm{~km}$, but a maximum is not seen. Nevertheless, the $\left[\mathrm{O}\left({ }^{3} \mathrm{P}\right)\right]$ in our study obtained above $95 \mathrm{~km}$ looks rather unexpected and possible reasons are discussed below.

The night-time $[\mathrm{H}]$ derived in this study shows a similar pattern to SABER $[\mathrm{H}]$, including the maximum at $80 \mathrm{~km}$. But best-fit model $[\mathrm{H}]$ is systematically larger than SABER $[\mathrm{H}]$ by a factor of approximately 1.5 . This is primarily caused by our faster $\mathrm{OH}(v=8)+\mathrm{O}_{2}$ rate compared to the rate applied in Mlynczak et al. (2018). Similar to the comparisons with $\left[\mathrm{O}\left({ }^{3} \mathrm{P}\right)\right]$, best-fit model $[\mathrm{H}]$ results also shows unexpected patterns above $95 \mathrm{~km}$.

The quality of the derived profiles is primarily affected by three different uncertainty sources. The first source includes uncertainties due to the rates of chemical and physical processes as well as the background atmosphere considered in the best-fit model. We assessed the $1 \sigma$ uncertainty by assuming uncorrelated input parameters. Adler-Golden (1997) did not state any uncertainties for $f_{9}$ and $f_{8}$, but these values should be similar to the uncertainty of $f_{8}$ derived by Klenerman and Smith (1987). Therefore, we applied an uncertainty of 0.03 for $f_{9}$ and $f_{8}$. In case of the Einstein coefficient, we adapted an uncertainty of $30 \%$, which is based on the five sets of Einstein coefficients analysed in Sect. 3.1. Note that larger uncertainties only occur for multi-quanta transitions $>2$ quanta. But $\left[\mathrm{O}\left({ }^{3} \mathrm{P}\right)\right]$ and $[\mathrm{H}]$ were calculated from the transition $\mathrm{OH}(9-7)+\mathrm{OH}(8-6)$, where the agreement is better. All the other $1 \sigma$ uncertainties of the input parameters were taken from their respective studies.

Recent comparisons between MIPAS $\mathrm{O}_{3}$ and SABER $\mathrm{O}_{3}$ derived at $9.6 \mu \mathrm{m}$ were performed by López-Puertas et al. (2018). The authors showed that night-time $\mathrm{O}_{3}$ from SABER is slightly larger than night-time $\mathrm{O}_{3}$ obtained from MIPAS in the altitude region $80-100 \mathrm{~km}$ over the Equator (their Figs. 8 and 10), but these differences are within the corresponding errors. Thus, at least to our knowledge, there is no conclusive evidence stating that SABER night-time $\mathrm{O}_{3}$ is generally too large. Nevertheless, we considered an uncertainty of $\mathrm{O}_{3}$ of about $10 \%$ (Smith et al., 2013). The uncertainty of SABER temperature was estimated to be lower than $3 \%$ (García-Comas et al., 2008), while the total uncertainty of the SABER OH(9-7)+OH(8-6) VER was assumed to be about $6 \%$ (see Sect. 2.1.2). The total $1 \sigma$ uncertainty was obtained by calculating the root-sum-square of all individual uncertainties. The results of $1 \sigma$ uncertainty of $\left[\mathrm{O}\left({ }^{3} \mathrm{P}\right)\right]$ and $[\mathrm{H}]$ derived by the best-fit model are shown as error bars in Fig. 6. The error bars of SABER $\left[\mathrm{O}\left({ }^{3} \mathrm{P}\right)\right]$ and $[\mathrm{H}]$ were adapted from the corresponding publication.

In case of the best-fit model $\left[\mathrm{O}\left({ }^{3} \mathrm{P}\right)\right]$ profile, the $1 \sigma$ uncertainty varies between $30 \%$ and $40 \%$, depending on altitude. 

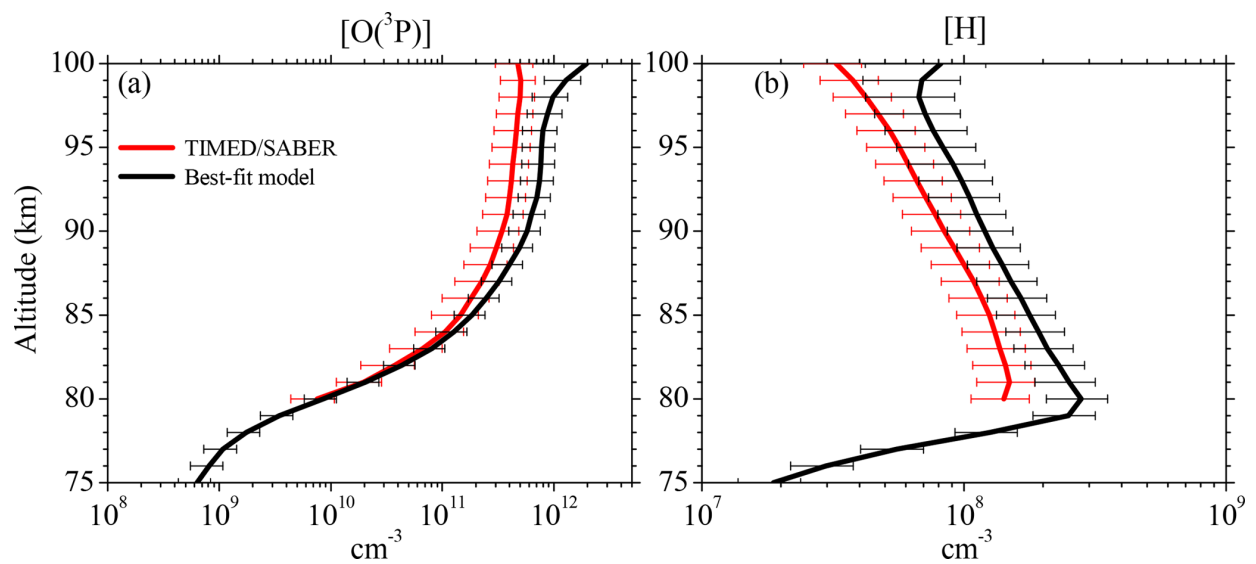

Figure 6. Vertical profiles of $(\mathbf{a})\left[\mathrm{O}\left({ }^{3} \mathrm{P}\right)\right]$ and $(\mathbf{b})[\mathrm{H}]$ derived from the SABER $\mathrm{OH}(9-7)+\mathrm{OH}(8-6)$ VER observations (Mlynczak et al., 2018) and our best-fit model by fitting the SABER OH(9-7)+OH(8-6) VER and OH(5-3)+OH(4-2) VER, as well as the SCIAMACHY OH(6-2) VER and $\mathrm{OH}(3-1)$ VER. Shown are averages of night-time mean zonal means of co-location measurements (see Sect. 2.2) from 2003 to 2011 between 0 and $10^{\circ} \mathrm{N}$. Error bars show the $1 \sigma$ uncertainty due to chemical and physical processes.

The individual contributions of the input parameters to the total $1 \sigma$ uncertainty are considerably different. Einstein coefficients and nascent distribution each account for about $10 \%$ and $5 \%$, respectively, throughout the entire height interval. The influence of the collision rates is about $5 \%$ and gradually decreases to zero with increasing altitude. In contrast, the chemical reaction rates $k_{2}$ and $k_{3}$ account for $\sim 80 \%$ to $\sim 85 \%$ of the overall $1 \sigma$ uncertainty of the derived $\left[\mathrm{O}\left({ }^{3} \mathrm{P}\right)\right]$ profiles. The total $1 \sigma$ uncertainty of $[\mathrm{H}]$ varies between $25 \%$ and $40 \%$ with $k_{1}$ being the major uncertainty source $(\sim 80 \%)$ below $85 \mathrm{~km}$. In higher-altitude regions, the impact due to uncertainty of $\left[\mathrm{O}\left({ }^{3} \mathrm{P}\right)\right]$ becomes gradually more important and both $k_{1}$ and $\left[\mathrm{O}\left({ }^{3} \mathrm{P}\right)\right]$ each contribute close to onehalf of the overall uncertainty at altitudes $>95 \mathrm{~km}$. We further assumed a worst case scenario (not shown here), meaning that all uncertainties of the input parameters contribute to either higher or lower $\left[\mathrm{O}\left({ }^{3} \mathrm{P}\right)\right]$ values, obtaining a worst case $1 \sigma$ uncertainty of approximately $80 \%$ for $\left[\mathrm{O}\left({ }^{3} \mathrm{P}\right)\right]$ and about $65 \%$ for $[\mathrm{H}]$. However, it is more likely that the uncertainties are uncorrelated since they originate from independent measurements.

The second aspect influencing the quality of the derived profiles is the assumption of chemical equilibrium of $\mathrm{O}_{3}$, represented by Eq. (3). This issue was recently investigated by Kulikov et al. (2018), who carried out simulations with a 3-D chemical transport model and demonstrated that a wrongly assumed chemical equilibrium of $\mathrm{O}_{3}$ may lead to considerable errors of derived $\left[\mathrm{O}\left({ }^{3} \mathrm{P}\right)\right]$ and $[\mathrm{H}]$. In order to test the validity of chemical equilibrium of $\mathrm{O}_{3}$ locally, the authors suggested that the $\mathrm{OH}(9-7)+\mathrm{OH}(8-6)$ VER has to exceed $10 \times G \times B$, with $B$ including several chemical reaction rates involving $\mathrm{O}_{x}$ and $\mathrm{HO}_{x}$ species. Note that this criterion requires simultaneously performed temperature and $\mathrm{OH}$ airglow measurements. Furthermore, this criterion is based on the assumption that the impact of atmospheric transport on chemical equilibrium of $\mathrm{O}_{3}$ is negligible. Since our experiments fit these conditions, we applied their suggested limit and found that in our case chemical equilibrium of $\mathrm{O}_{3}$ is valid above $80 \mathrm{~km}$. We have to point out that the term "chemical equilibrium of $\mathrm{O}_{3}$ " refers to $\mathrm{O}_{3}$ that does not deviate more than $10 \%$ from $\mathrm{O}_{3}$ in chemical equilibrium (Kulikov et al., 2018, their Eq. 2). Assuming that $\mathrm{O}_{3}$ is always $10 \%$ greater or lesser than $\mathrm{O}_{3}$ in chemical equilibrium introduces an uncertainty of about $10 \%$ at $80 \mathrm{~km}$ and $20 \%$ at $95 \mathrm{~km}$, in addition to the total uncertainty of $\left[\mathrm{O}\left({ }^{3} \mathrm{P}\right)\right]$ and $[\mathrm{H}]$ estimated above. However, such a worst case scenario is rather unlikely, whereas it is more realistic that $\mathrm{O}_{3}$ actually varies around its chemical equilibrium concentration. Thus, an over- and underestimation of derived $\left[\mathrm{O}\left({ }^{3} \mathrm{P}\right)\right]$ and $[\mathrm{H}]$ are assumed to compensate for each other. Consequently, we conclude that the impact on the total uncertainty of $\left[\mathrm{O}\left({ }^{3} \mathrm{P}\right)\right]$ and $[\mathrm{H}]$ due to deviations from chemical equilibrium of $\mathrm{O}_{3}$ is negligible, but only because the previously used criterion $(\mathrm{OH}(9-7)+\mathrm{OH}(8$ 6) VER $>10 \times G \times B$ ) is valid.

The last problem lies in the fact that the approach used here (see Sect. 2.2) has to be applied to individual $\mathrm{OH}$ airglow profiles to derive $\left[\mathrm{O}\left({ }^{3} \mathrm{P}\right)\right]$ and $[\mathrm{H}]$ correctly. However, the individual scans of $\mathrm{OH}(6-2)$ were too noisy to analyse single profiles and we therefore used climatology for all input parameters. By investigating individual $\mathrm{OH}$ airglow profiles, we derive individual $\left[\mathrm{O}\left({ }^{3} \mathrm{P}\right)\right]$ profiles and eventually average them to the mean $\left[\mathrm{O}\left({ }^{3} \mathrm{P}\right)\right]$ profile. While in our case, we directly derive the mean $\left[\mathrm{O}\left({ }^{3} \mathrm{P}\right)\right]$ profile. This makes no difference as long as the relation between $\mathrm{OH}$ airglow and $\left[\mathrm{O}\left({ }^{3} \mathrm{P}\right)\right]$ is a linear one. But Eq. (4b) shows that the relation between $\left[\mathrm{O}\left({ }^{3} \mathrm{P}\right)\right]$ and the $\mathrm{OH}(9-7)+\mathrm{OH}(8-6)$ VER is only approximately linear because $G$ also depends on $\left[\mathrm{O}\left({ }^{3} \mathrm{P}\right)\right]$, as represented by the terms $C_{v}$ and $C_{v v^{\prime}}$. The linearity between the $\mathrm{OH}(9-7)+\mathrm{OH}(8-6)$ VER and $\left[\mathrm{O}\left({ }^{3} \mathrm{P}\right)\right]$ of an air parcel with a certain temperature and pressure is solely con- 


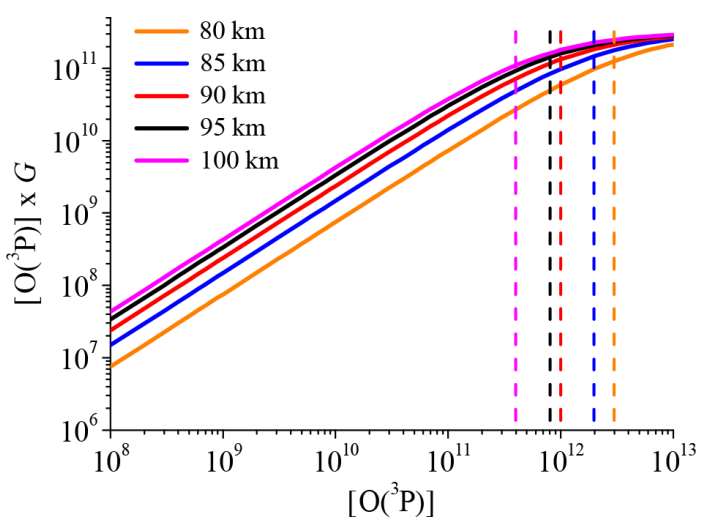

Figure 7. $\mathrm{O}\left({ }^{3} \mathrm{P}\right) \times G$ as a function of $\mathrm{O}\left({ }^{3} \mathrm{P}\right)$ at different altitudes. The visually determined upper limits of $\mathrm{O}\left({ }^{3} \mathrm{P}\right)$ before non-linearity becomes too pronounced are represented by the dashed lines.

trolled by $\left[\mathrm{O}\left({ }^{3} \mathrm{P}\right)\right] \times G$. Note that $[\mathrm{H}]$ too is affected by this non-linearity issue since $[\mathrm{H}]$ depends on $G$ (Eq. 4a). Thus, derived $[\mathrm{H}]$ values are only reliable as long as the derived $\left[\mathrm{O}\left({ }^{3} \mathrm{P}\right)\right]$, and as a consequence $G$, is not seriously in error.

In order to test the linearity, $\left[\mathrm{O}\left({ }^{3} \mathrm{P}\right)\right] \times G$ was plotted as a function of $\left[\mathrm{O}\left({ }^{3} \mathrm{P}\right)\right]$ and the corresponding results for bestfit model at five different heights are presented in Fig. 7. It is seen that the relation between $\left[\mathrm{O}\left({ }^{3} \mathrm{P}\right)\right]$ and $\left[\mathrm{O}\left({ }^{3} \mathrm{P}\right)\right] \times G$ or the $\mathrm{OH}(9-7)+\mathrm{OH}(8-6) \mathrm{VER}$, respectively, is linear for small values of $\left[\mathrm{O}\left({ }^{3} \mathrm{P}\right)\right]$, while a non-linear behaviour becomes more pronounced for larger values of $\left[\mathrm{O}\left({ }^{3} \mathrm{P}\right)\right]$. Furthermore, the starting point of the behaviour is shifted to lower $\left[\mathrm{O}\left({ }^{3} \mathrm{P}\right)\right]$ values at higher altitudes. In order to estimate this threshold, we performed a visual analysis and determined an upper limit of $\left[\mathrm{O}\left({ }^{3} \mathrm{P}\right)\right]$ before non-linearity of $\left[\mathrm{O}\left({ }^{3} \mathrm{P}\right)\right] \times G$ takes over. The approximated upper limits are added as dashed lines in Fig. 7. Finally, an $\left[\mathrm{O}\left({ }^{3} \mathrm{P}\right)\right]$ value at a certain altitude is assumed to be true if this value is below the corresponding upper limit of $\left[\mathrm{O}\left({ }^{3} \mathrm{P}\right)\right]$. Otherwise, it should be viewed more critically. This was done for each altitude and we found that the $\left[\mathrm{O}\left({ }^{3} \mathrm{P}\right)\right]$ and $[\mathrm{H}]$ profiles presented in Fig. 6 are plausible in the altitude region $<95 \mathrm{~km}$. In combination with the estimation of chemical equilibrium of $\mathrm{O}_{3}$ and the maximum of physically allowed $\left[\mathrm{O}\left({ }^{3} \mathrm{P}\right)\right]$, we think that the $\left[\mathrm{O}\left({ }^{3} \mathrm{P}\right)\right]$ and $[\mathrm{H}]$ derived by the best-fit model are reasonable results between 80 and $95 \mathrm{~km}$. Note that these altitude limits do not affect the results with respect to $\mathrm{OH}(v)+\mathrm{O}_{2}$ and $\mathrm{OH}(v)+\mathrm{O}\left({ }^{3} \mathrm{P}\right)$ presented in the Sect. 3.2 and 3.3.

\section{Conclusions}

We presented a zero-dimensional box model which fits the VER of four different $\mathrm{OH}$ airglow observations, namely TIMED/SABER OH(9-7)+OH(8-6) and $\mathrm{OH}(5-3)+\mathrm{OH}(4-2)$ as well as ENVISAT/SCIAMACHY $\mathrm{OH}(6-2)$ and $\mathrm{OH}(3-$ 1). Based on a night-time mean zonal-mean climatology of co-location measurements between 2003 and 2011 at $0-10^{\circ} \mathrm{N}$, we found that (i) $\mathrm{OH}(v)+\mathrm{O}_{2}$ is likely to occur via multi-quantum deactivation, while $\mathrm{OH}(v \geq 7)$ primarily contributes to $\mathrm{OH}(v \leq 5)$ and might prefer deactivation to $\mathrm{OH}\left(v^{\prime}=v-5\right)+\mathrm{O}_{2}$. This relaxation scheme generally agrees with results reported in Russell et al. (2005) but is considerably different to the commonly used scheme suggested by Adler-Golden (1997). We further found (ii) general support for the new pathway $\mathrm{OH}(v)+\mathrm{O}\left({ }^{3} \mathrm{P}\right) \rightarrow \mathrm{OH}\left(v^{\prime}\right)+\mathrm{O}\left({ }^{1} \mathrm{D}\right)$ proposed by Sharma et al. (2015) but suggest slower total loss rates of $\mathrm{OH}(v=8,7,6,5)+\mathrm{O}\left({ }^{3} \mathrm{P}\right)$. Additionally, hints of a favoured deactivation to $\mathrm{OH}\left(v^{\prime}=v-5\right)+\mathrm{O}\left({ }^{1} \mathrm{D}\right)$ are obtained.

We have to stress that we performed an empirical model study and the total rates and deactivation channels suggested here heavily depend on the $\mathrm{OH}$ transitions considered. Including additional $\mathrm{OH}$ transitions, like $\mathrm{OH}(9-4), \mathrm{OH}(8-3)$, and $\mathrm{OH}(5-1)$ from the Optical Spectrograph and InfraRed Imager System (OSIRIS) on board the Odin satellite, might result in other values and deactivation schemes. This could be a subject of a future study. Also note that the Einstein coefficients used here might be in error (see Sect. 3.1; Fig. 2). This does not affect the two general conclusions drawn above but impacts the empirically derived rates.

Furthermore, our $\mathrm{OH}$ airglow model is based on the transitions $\mathrm{OH}(9-7)+\mathrm{OH}(8-6), \mathrm{OH}(6-2), \mathrm{OH}(5-3)+\mathrm{OH}(4-2)$, and $\mathrm{OH}(3-1)$ only. Therefore, our model does not provide any information of $\mathrm{OH}(v \leq 2)$. It further cannot distinguish between $\mathrm{OH}(v=5)$ and $\mathrm{OH}(v=4)$, as well as $\mathrm{OH}(v=9)$ and $\mathrm{OH}(v=8)$, respectively, and errors in $\mathrm{OH}(v=5)$ and $\mathrm{OH}(v=9)$ might be compensated for by errors in $\mathrm{OH}(v=4)$ and $\mathrm{OH}(v=8)$ or vice versa. Consequently, the rates of the individual deactivation channels presented in Table 2 and Table 3 should be viewed as a suggestion only. In particular, the rate of $\mathrm{OH}(v=9)+\mathrm{O}\left({ }^{3} \mathrm{P}\right) \rightarrow \mathrm{OH}(v=3)+\mathrm{O}\left({ }^{1} \mathrm{D}\right)$ is about 3 times slower than the lower limit reported by Kalogerakis et al. (2016). But these issues will only be solved eventually when future laboratory experiments provide the corresponding $\mathrm{OH}(v)+\mathrm{O}_{2}$ and $\mathrm{OH}(v)+\mathrm{O}\left({ }^{3} \mathrm{P}\right)$ relaxation rates and deactivation channels. Nevertheless, we have to emphasize that the shortcomings of our model do not affect the two main conclusions drawn in this study.

Justified by a nearly linear relation between $\left[\mathrm{O}\left({ }^{3} \mathrm{P}\right)\right]$ and the $\mathrm{OH}(9-7)+\mathrm{OH}(8-6) \mathrm{VER}$, the physically allowed upper limit of $\left[\mathrm{O}\left({ }^{3} \mathrm{P}\right)\right]$, and also considering the chemical equilibrium of $\mathrm{O}_{3}$, we conclude that the $\left[\mathrm{O}\left({ }^{3} \mathrm{P}\right)\right]$ and $[\mathrm{H}]$ profiles derived by the best-fit model are plausible in the altitude range from 80 to $95 \mathrm{~km}$. The corresponding $1 \sigma$ uncertainty due to uncertainties of chemical reactions and physical processes varies between $35 \%$ and $40 \%([\mathrm{H}])$ and between $30 \%$ and $40 \%\left(\left[\mathrm{O}\left({ }^{3} \mathrm{P}\right)\right]\right)$, depending on altitude.

The $[\mathrm{H}]$ derived here is systematically larger by a factor of 1.5 than SABER $[\mathrm{H}]$ reported in Mlynczak et al. (2018), which is primarily attributed to their slower $\mathrm{OH}(v=8)+\mathrm{O}_{2}$ rate. Our $\left[\mathrm{O}\left({ }^{3} \mathrm{P}\right)\right]$ values in the altitude region below $\sim 87 \mathrm{~km}$ 
are in agreement within the corresponding errors with the results found in Mlynczak et al. (2018) and Zhu and Kaufmann (2018) but are lower than the values presented in Panka et al. (2018). However, we think that the results of the latter study are too large because the authors falsely assumed too fast $\mathrm{OH}(v)+\mathrm{O}_{2}$ rates. In the altitude region above $\sim 87 \mathrm{~km}$, the $\left[\mathrm{O}\left({ }^{3} \mathrm{P}\right)\right]$ shown here is generally larger than the values reported in these three studies up to a factor 1.5 to 1.7 . These differences are attributed to the faster rates and different deactivation channels of $\mathrm{OH}(v)+\mathrm{O}\left({ }^{3} \mathrm{P}\right)$. Therefore, it is indicated that we might overestimate $\left[\mathrm{O}\left({ }^{3} \mathrm{P}\right)\right]$ above $>87 \mathrm{~km}$ and we suggest that our results should be interpreted as an upper limit. However, a final conclusion cannot be drawn at this point due the large uncertainties of the rates assumed to derive $\left[\mathrm{O}\left({ }^{3} \mathrm{P}\right)\right]$.

Data availability. The data used in this study are open to the public. The SABER data are maintained by the corresponding SABER team, including several scientists. Further information and support can be obtained by contacting the SABER support team (saber@gats-inc.com). The TIMED/SABER data can be downloaded from http://saber.gats-inc.com/data.php (last access: 4 May 2017), while ENVISAT/SCIAMACHY can be accessed by getting in contact with Christian von Savigny (csavigny@physik.uni-greifswald.de).

Author contributions. MS initialized and supervised the study. CVS retrieved the SCIAMACHY data. TF performed the model runs and wrote the final paper with contributions from all coauthors.

Competing interests. The authors declare that they have no conflict of interest.

Special issue statement. This article is part of the special issue "Layered phenomena in the mesopause region (ACP/AMT interjournal SI)". It is a result of the LPMR workshop 2017 (LPMR2017), Kühlungsborn, Germany, 18-22 September 2017.

Acknowledgements. Tilo Fytterer and Miriam Sinnhuber gratefully acknowledge funding by the Deutsche Forschungsgemeinschaft (DFG), grant SI 1088/6-1. The authors also acknowledge support by the Open Access Publishing Fund of Karlsruhe Institute of Technology.

The article processing charges for this open-access

publication were covered by a Research

Centre of the Helmholtz Association.

Edited by: William Ward

Reviewed by: two anonymous referees

\section{References}

Adler-Golden, S.: Kinetic parameters for $\mathrm{OH}$ nightglow modeling consistent with recent laboratory measurements, J. Geophys. Res., 102, 19969-19976, https://doi.org/10.1029/97JA01622, 1997.

Adrews, D. G., Holton, J. R., and Leovy, C. B. (Eds.): Middle Atmosphere Dynamics, Academic Press, Orlando, USA, 1987.

Anlauf, K. G., MacDonald, R. G., and Polanyi, J. C.: Infrared chemiluminescence from $\mathrm{H}+\mathrm{O}_{3}$ at low pressure, Chem. Phys. Lett, 1, 619-622, https://doi.org/10.1016/0009-2614(68)800971,1968

Bovensmann, H., Burrows, J. P., Buchwitz, M., Frerick, J., Noël, S., Rozanov, V. V., Chance, K. V., and Goede, A. P. H.: SCIAMACHY: Mission objectives and measurement modes, J. Atmos. Sci., 56, 127-150, https://doi.org/10.1175/15200469(1999)056<0127:SMOAMM>2.0.CO;2, 1999.

Bramstedt, K., Noël, S., Bovensmann, H., Gottwald, M., and Burrows, J. P.: Precise pointing knowledge for SCIAMACHY solar occultation measurements, Atmos. Meas. Tech., 5, 2867-2880, https://doi.org/10.5194/amt-5-2867-2012, 2012.

Brooke, J. S. A., Bernath, P. F., Western, C. M., Sneden, C., Afsar, M., Li, G., and Gordon, I. E.: Line strengths of rovibrational and rotational transitions in the $X^{2} \Pi$ ground state of OH, J. Quant. Spectrosc. Ra., 168, 142-157, https://doi.org/10.1016/j.jqsrt.2015.07.021, 2016.

Burkholder, J. B., Sander, S. P., Abbatt, J., Barker, J. R., Huie, R. E., Kolb, C. E., Kurylo, M. J., Orkin, V. L., Wilmouth, D. M., and Wine, P. H.: Chemical Kinetics and Photochemical Data for Use in Atmospheric Studies, Evaluation No. 18, JPL Publication 15-10, Jet Propulsion Laboratory, Pasadena, available at: http: //jpldataeval.jpl.nasa.gov (last access: 16 August 2016), 2015.

Burtt, K. D. and Sharma, R. D.: Near-resonant energy transfer from highly vibrationally excited $\mathrm{OH}$ to $\mathrm{N}_{2}$, J. Chem. Phys., 128, 1243111-1243118, https://doi.org/10.1063/1.2884343, 2008.

Caridade, P. J. S. B., Sabin, J., Garridoz, J. D., and Varandas, A. J. C.: Dynamics of $\mathrm{OH}+\mathrm{O}_{2}$ vibrational relaxation processes, Phys. Chem. Chem. Phys., 4, 4959-4969, https://doi.org/10.1039/b203101a, 2002.

Caridade, P. J. S. B., Horta, J.-Z. J., and Varandas, A. J. C.: Implications of the $\mathrm{O}+\mathrm{OH}$ reaction in hydroxyl nightglow modeling, Atmos. Chem. Phys., 13, 1-13, https://doi.org/10.5194/acp-131-2013, 2013.

Chalamala, B. R. and Copeland, R. A.: Collision dynamics of $\mathrm{OH}\left(X^{2} \Pi, v=9\right)$, J. Chem. Phys., 99, 5807-5811, https://doi.org/10.1063/1.465932, 1993.

Charters, P. E., Macdonald, R. G., and Polanyi, J. C.: Formation of vibrationally excited $\mathrm{OH}$ by the reaction $\mathrm{H}+\mathrm{O}_{3}$, Appl. Optics, 10, 1747-1754, https://doi.org/10.1364/AO.10.001747, 1971.

Dodd, J. A., Lipson, S. J., and Blumberg, W. A. M.: Formation and vibrational relaxation of $\mathrm{OH}\left(X^{2} \Pi_{i}, v\right)$ by $\mathrm{O}_{2}$ and $\mathrm{CO}_{2}$, J. Chem. Phys., 95, 5752-5762, https://doi.org/10.1063/1.461597, 1991.

Dyer, M. J., Knutsen, K., and Copeland, R. A.: Energy transfer in the ground state of $\mathrm{OH}$ : Measurements of $\mathrm{OH}(v=8,10,11)$ removal, J. Chem. Phys., 107, 7809-7815, https://doi.org/10.1063/1.475094, 1997.

Finlayson-Pitts, B. J. and Kleindienst, T. E.: The reaction of hydrogen atoms with ozone as a source of vibrationally excited $\mathrm{OH}\left(X^{2} \Pi_{i}\right)_{v=9}$ for kinetic studies, J. Chem. Phys., 74, 56435658, https://doi.org/10.1063/1.440928, 1981. 
García-Comas, M., López-Puertas, M., Marshall, B. T., Wintersteiner, P. P., Funke, B., Bermejo-Pantaleón, D., Mertens, C. J., Remsberg, E. E., Gordley, L. L., Mlynczak, M. G., and Russell III, J. M.: Errors in Sounding of the Atmosphere using Broadband Emission Radiometry (SABER) kinetic temperature caused by non-local-thermodynamicequilibrium model parameters, J. Geophys. Res., 113, D24106, https://doi.org/10.1029/2008JD010105, 2008.

Good, R. E.: Determination of atomic oxygen density from rocket borne measurements of hydroxyl airglow, Planet. Space Sci., 24, 389-395, https://doi.org/10.1016/0032-0633(76)90052-0, 1976.

Gottwald, M., Krieg, E., von Savigny, C., Noël, S., Bovensmann, H., and Bramstedt, K.: Determination of SCIAMACHY Line of Sight Misalignments, Proceedings of the Envisat Atmospheric Science Conference, ESA SP-636, Montreux, Switzerland, 2327 April 2007.

Grygalashvyly, M., Sonnemann, G. R., Lübken, F.-J., Hartogh, P., and Berger, U.: Hydroxyl layer: Mean state and trends at midlatitudes, J. Geophys. Res.-Atmos., 119, 12391-12419, https://doi.org/10.1002/2014JD022094, 2014.

Howell, C. D., Michelangeli, D. V., Allen, M., Yung, Y. L., and Thomas, R. J.: SME observations of $\mathrm{O}_{2}\left({ }^{1} \Delta_{\mathrm{g}}\right)$ nightglow: An assessment of the chemical production mechanisms, Planet. Space Sci., 38, 529-537, https://doi.org/10.1016/0032-0633(90)90145G, 1990 .

Kalogerakis, K. S., Smith, G. P., and Copeland, R. A.: Collisional removal of $\mathrm{OH}\left(X^{2} \Pi, \quad v=9\right)$ by $\mathrm{O}, \mathrm{O}_{2}$, $\mathrm{O}_{3}, \mathrm{~N}_{2}$, and $\mathrm{CO}_{2}$, J. Geophys. Res., 116, D20307, https://doi.org/10.1029/2011JD015734, 2011.

Kalogerakis, K. S., Matsiev, D., Sharma, R. D., and Wintersteiner, P. P.: Resolving the mesospheric nighttime $4.3 \mu \mathrm{m}$ emission puzzle: Laboratory demonstration of new mechanism for $\mathrm{OH}(v)$ relaxation, Geophys. Res. Lett., 43, 8835-8843, https://doi.org/10.1002/2016GL069645, 2016.

Kaufmann, M., Lehmann, C., Hoffmann, L., Funke, B., LopezPuertas, M., von Savigny, C., and Riese, M.: Chemical heating rates derived from SCIAMACHY vibrationally excited OH limb emission spectra, Adv. Space Res., 41, 1914-1920, https://doi.org/10.1016/j.asr.2007.07.045, 2008.

Klenerman, D. and Smith, I. W. M.: Infrared chemiluminescence studies using a SISAM spectrometer, J. Chem. Soc., Faraday Trans., 2, 83, 229-241, https://doi.org/10.1039/F29878300229, 1987.

Knutsen, K., Dyer, M. J., and Copeland, R. A.: Collisional removal of $\mathrm{OH}\left(X^{2} \Pi\right), v=7$ ) by $\mathrm{O}_{2}, \mathrm{~N}_{2}, \mathrm{CO}_{2}$, and $\mathrm{N}_{2} \mathrm{O}$, J. Chem. Phys., 104, 5798-5802, https://doi.org/10.1063/1.471311, 1996.

Kulikov, M. Y., Belikovich, M. V., Grygalashvyly, M., Sonnemann, G. R., Ermakova, T. S., Nechaev, A. A., and Feigin, A. M.: Nighttime ozone chemical equilibrium in the mesopause region, J. Geophys. Res.-Atmos., 123, 1-15, https://doi.org/10.1002/2017JD026717, 2018.

Lacoursiere, J., Dyer, M. J., and Copeland, R. A.: Temperature dependence of the collisional energy transfer of $\mathrm{OH}(v=10)$ between 220 and $310 \mathrm{~K}$, J. Chem. Phys., 118, 1661-1667, https://doi.org/10.1063/1.1530581, 2003.

López-Puertas, M., García-Comas, M., Funke, B., Picard, R. H., Winick, J. R., Wintersteiner, P. P., Mlynczak, M. G., Mertens, C. J., Russell III, J. M., and Gordley, L. L.: Evidence for an $\mathrm{OH}(v)$ excitation mechanism of $\mathrm{CO}_{2} 4.3 \mu \mathrm{m}$ nighttime emission from
SABER/TIMED measurements, J. Geophys. Res., 109, D09307, https://doi.org/10.1029/2003JD004383, 2004.

López-Puertas, M., García-Comas, M., Funke, B., Gardini, A., Stiller, G. P., von Clarmann, T., Glatthor, N., Laeng, A., Kaufmann, M., Sofieva, V. F., Froidevaux, L., Walker, K. A., and Shiotani, M.: MIPAS observations of ozone in the middle atmosphere, Atmos. Meas. Tech., 11, 2187-2212, https://doi.org/10.5194/amt-11-2187-2018, 2018.

Meinel, A. B.: OH Emission Bands in the Spectrum of the Night Sky. II, Astrophys. J., 112, 120-130, https://doi.org/10.1086/145321, 1950.

Mlynczak, M. G. and Solomon, S.: A detailed evaluation of the heating efficiency in the middle atmosphere, J. Geophys. Res., 98, 10517-10541, https://doi.org/10.1029/93JD00315, 1993.

Mlynczak, M. G., Martin-Torres, F. J., Johnson, D. G., Kratz, D. P., Traub, W. A., and Jucks, K.: Observations of the $\mathrm{O}\left({ }^{3} \mathrm{P}\right)$ fine structure line at $63 \mathrm{~mm}$ in the upper mesosphere and lower thermosphere, J. Geophys. Res., 109, A12306, https://doi.org/10.1029/2004JA010595, 2004.

Mlynczak, M. G., Martin-Torres, F. J., Crowley, G., Kratz, D. P., Funke, B., Lu, G., Lopez-Puertas, M., Russell III, J. M., Kozyra, J., Mertens, C., Sharma, R., Gordley, L., Picard, R., Winick, J., and Paxton, L.: Energy transport in the thermosphere during the solar storms of April 2002, J. Geophys. Res., 110, A12S25, https://doi.org/10.1029/2005JA011141, 2005.

Mlynczak, M. G., Hunt, L. A., Mast, J. C., Marshall, B. T., Russell III, J. M., Smith, A. K., Siskind, D. E., Yee, J.-H., Mertens, C. J., Martin-Torres, F. J., Thompson, R. E., Drob, D. P., and Gordley L. L.: Atomic oxygen in the mesosphere and lower thermosphere derived from SABER: Algorithm theoretical basis and measurement uncertainty, J. Geophys. Res.-Atmos., 118, 5724 5735, https://doi.org/10.1002/jgrd.50401, 2013a.

Mlynczak, M. G., Hunt, L. H., Mertens, C. J., Marshall, B. T., Russell III, J. M., López-Puertas, M., Smith, A. K., Siskind, D. E., Mast, J. C., Thompson, R. E., and Gordley, L. L.: Radiative constraints on the global annual mean atomic oxygen concentration in the mesopause region, J. Geophys., Res.-Atmos., 118, 57965802, https://doi.org/10.1002/jgrd.50400, 2013b.

Mlynczak, M. G., Hunt, L. A., Marshall, B. T., Mertens, C. J., Marsh, D. R., Smith, A. K., Russell III, J. M., Siskind, D. E., and Gordley, L. L.: Atomic hydrogen in the mesopause region derived from SABER: Algorithm theoretical basis, measurement uncertainty, and results, J. Geophys. Res.-Atmos., 119, 35163526, https://doi.org/10.1002/2013JD021263, 2014.

Mlynczak, M. G., Hunt, L. A., Russell III, J. M., and Marshall, B. T.: Updated SABER Night Atomic Oxygen and Implications for SABER Ozone and Atomic Hydrogen, Geophys. Res. Lett., 45, 5735-5741, https://doi.org/10.1029/2018GL077377, 2018.

Murtagh, D. P., Witt, G., Stegman, J., McDade, J. C., Llewellyn, E. J., Harris, F., and Greer, R. G. H.: An assessment of proposed $\mathrm{O}\left({ }^{1} \mathrm{~S}\right)$ and $\mathrm{O}_{2}\left(b^{1} \Sigma_{\mathrm{g}}^{+}\right)$nightglow excitation parameters, Planet. Space Sci., 38, 43-53, https://doi.org/10.1016/00320633(90)90004-A, 1990.

Nelson Jr., D. D., Schiffman, A., Nesbitt, D. J., Orlando, J. J., and Burkholder, J. B.: $\mathrm{H}+\mathrm{O}_{3}$ Fourier-transform infrared emission and laser absorption sudies of $\mathrm{OH}\left(X^{2} \Pi\right)$ radical: An experimental dipole moment function and state-tostate Einstein A coefficients, J. Chem. Phys., 93, 7003-7019, https://doi.org/10.1063/1.459476, 1990. 
Ohoyama, H., Kasai, T., Yoshimura, Y., Kimura, H., and Kuwata, $\mathrm{K}$.: Initial distribution of vibration of the $\mathrm{OH}$ radicals produced in the $\mathrm{H}+\mathrm{O}_{3} \rightarrow \mathrm{OH}\left(X^{2} \Pi_{1 / 2,3 / 2}\right)+\mathrm{O}_{2}$ reaction: Chemiluminescence by a crossed beam technique, Chem. Phys. Lett., 118, 263266, https://doi.org/10.1016/0009-2614(85)85312-4, 1985.

Panka, P. A., Kutepov, A. A., Kalogerakis, K. S., Janches, D., Russell, J. M., Rezac, L., Feofilov, A. G., Mlynczak, M. G., and Yigit, E.: Resolving the mesospheric nighttime $4.3 \mu \mathrm{m}$ emission puzzle: comparison of the $\mathrm{CO}_{2}\left(v_{3}\right)$ and $\mathrm{OH}(v)$ emission models, Atmos. Chem. Phys., 17, 9751-9760, https://doi.org/10.5194/acp17-9751-2017, 2017.

Panka, P. A., Kutepov, A. A., Rezac, L., Kalogerakis, K. S., Feolilov, A. G., Marsh, D., Janches, D., and Yigit, E.: Atomic Oxygen Retrieved From the SABER 2.0- and 1.6- $\mu$ m Radiances Using New First-Principles Nighttime $\mathrm{OH}(v)$ Model, Geophys. Res. Lett., 45, 5798-5803, https://doi.org/10.1029/2018GL077677, 2018.

Rensberger, K. J., Jeffries, J. B., and Crosley, D. R.: Vibrational relaxation of $\mathrm{OH}\left(X^{2} \Pi_{i}, v=2\right)$, J. Chem. Phys., 90, 2174-2181, https://doi.org/10.1063/1.456671, 1989.

Rothman, L. S., Gordon, I. E., Barbe, A., Benner, D. C., Bernath, P. F., Birk, M., Boudon, V., Brown, L. R., Campargue, A., Champion, J.-P., Chance, K., Coudert, L. H., Danaj, V., Devi, V. M., Fally, S., Flaud, J.-M., Gamache, R. R., Goldmanm, A., Jacquemart, D., Kleiner, I., Lacome, N., Lafferty, W. J., Mandin, J.-Y., Massie, S. T., Mikhailenko, S. N., Miller, C. E., Moazzen-Ahmadi, N., Naumenko, O. V., Nikitin, A. V., Orphal, J., Perevalov, V. I., Perrin, A., Predoi-Cross, A., Rinsland, C. P., Rotger, M., Simeckova, M., Smith, M. A. H., Sung, K., Tashkun, S. A., Tennyson, J., Toth, R. A., Vandaele, A. C., and Vander Auwera, J.: The HITRAN 2008 molecular spectroscopic database, J. Quant. Spectrosc. Ra., 110, 533-572, https://doi.org/10.1016/j.jqsrt.2009.02.013, 2009.

Russell, J. P. and Lowe, R. P.: Atomic oxygen profiles (80$94 \mathrm{~km}$ ) derived from Wind Imaging Interferometer/Upper Atmospheric Research Satellite measurements of the hydroxyl airglow: 1. Validation of technique, J. Geophys. Res., 108, 4662, https://doi.org/10.1029/2003JD003454, 2003.

Russell III, J. M., Mlynczak, M. G., Gordley, L. L., Tansock, J., and Esplin, R.: An overview of the SABER experiment and preliminary calibration results, in Proceedings of the 44th Annual Meeting, Denver, Colorado, 18-23 July, 3756, 277-288, SPIE, Bellingham, WA, 1999.

Russell, J. P., Ward, W. E., Lowe, R. P., Roble, R. G., Shepherd, G. G., and Solheim, B.: Atomic oxygen profiles (80 to $115 \mathrm{~km}$ ) derived from Wind Imaging Interferometer/Upper Atmospheric Research Satellite measurements of the hydroxyl and greenline airglow: Local time-latitude dependence, J. Geophys. Res., 110, D15305, https://doi.org/10.1029/2004JD005570, 2005.

Sander, R., Baumgaertner, A., Gromov, S., Harder, H., Jöckel, P., Kerkweg, A., Kubistin, D., Regelin, E., Riede, H., Sandu, A., Taraborrelli, D., Tost, H., and Xie, Z.-Q.: The atmospheric chemistry box model CAABA/MECCA-3.0, Geosci. Model Dev., 4, 373-380, https://doi.org/10.5194/gmd-4-373-2011, 2011.

Shalashilin, D. V., Umanskii, S. Y., and Gershenzon, Y. M.: Dynamics of vibrational energy exchange in collisions of OH and OD radicals with $\mathrm{N}_{2}$, Application to the kinetics of $\mathrm{OH}$-vibrational deactivation in the upper atmosphere, Chem. Phys., 168, 315325, https://doi.org/10.1016/0301-0104(92)87165-6, 1992.
Shalashilin, D. V., Michtchenko, A. V., Umanskii, S. Y., and Gershenzon, Y. M.: Simulation of Effective VibrationalTranslational Energy Exchange in Collisions of Vibrationally Excited $\mathrm{OH}$ with $\mathrm{O}_{2}$ on the Model Potential Energy Surface. Can the Relaxation of $\mathrm{OH}(v)$ Be One-Quantum for Low and Multiquantum for High v?, J. Phys., Chem.-US, 99, 11627-11635, https://doi.org/10.1021/j100030a001, 1995.

Sharma, R. D., Wintersteiner, P. P., and Kalogerakis, K. S.: A new mechanism for $\mathrm{OH}$ vibrational relaxation leading to enhanced $\mathrm{CO}_{2}$ emissions in the nocturnal mesosphere, Geophys. Res. Lett. 42, 4639-4647, https://doi.org/10.1002/2015GL063724, 2015.

Sharp, W. E. and Kita, D.: In situ measurement of atomic hydrogen in the upper mesosphere, J. Geophys. Res.-Atmos., 92, 43194324, https://doi.org/10.1029/JD092iD04p04319, 1987.

Smith, A. K., Marsh, D. R., Mlynczak, M. G., and Mast, J. C.: Temporal variation of atomic oxygen in the upper mesosphere from SABER, J. Geophys. Res., 115, D18309, https://doi.org/10.1029/2009JD013434, 2010.

Smith, A. K., Harvey, V. L., Mlynczak, M. G., Funke, B., GarcíaComas, M., Hervig, M., Kaufmann, M., Kyrölä, E., LópezPuertas, M., McDade, I., Randall, C. E., Rusell III, J. M., Sheese, P. E., Shiotani, M., Skinner, W. R., Suzuki, M., and Walker, K. A.: Satellite observations of ozone in the upper mesosphere, J. Geophys. Res.-Atmos., 118, 5803-5821, https://doi.org/10.1002/jgrd.50445, 2013.

Streit, G. E. and Johnston, H. S.: Reactions and quenching of vibrationally excited hydroxyl radicals, J. Chem. Phys., 64, 95-103, https://doi.org/10.1063/1.431917, 1976.

Thiebaud, J. E., Copeland, R. A., and Kalogerakis, K. S.: Vibrational relaxation of $\mathrm{OH}(v=7)$ with $\mathrm{O}, \mathrm{O}_{2}$ and $\mathrm{H}$, Abstract SA43A-1752, Fall Meeting, AGU, San Francisco, Calif., 2010.

Turnbull, D. N. and Lowe, R. P.: New hydroxyl transition probabilities and their importance in airglow studies, Planet. Space Sci., 37, 723-738, https://doi.org/10.1016/0032-0633(89)90042$1,1989$.

Van der Loo, M. P. J. and Groenenboom, G. C.: Theoretical transition probabilities for the $\mathrm{OH}$ Meinel system, J. Chem. Phys., 126, 114413, https://doi.org/10.1063/1.2646859, 2007.

Varandas, A. J. C.: Reactive and non-reactive vibrational quenching in $\mathrm{O}+\mathrm{OH}$ collisions, Chem. Phys. Lett., 396, 182-190, https://doi.org/10.1016/j.cplett.2004.08.023, 2004.

Von Savigny, C. and Lednyts'kyy, O.: On the relationship between atomic oxygen and vertical shifts between $\mathrm{OH}$ Meinel bands originating from different vibrational levels, Geophys. Res. Lett., 40, 5821-5825, https://doi.org/10.1002/2013GL058017, 2013.

von Savigny, C., McDade, I. C., Eichmann, K.-U., and Burrows, J. P.: On the dependence of the $\mathrm{OH}^{*}$ Meinel emission altitude on vibrational level: SCIAMACHY observations and model simulations, Atmos. Chem. Phys., 12, 8813-8828, https://doi.org/10.5194/acp-12-8813-2012, 2012.

Xu, J., Gao, H., Smith, A. K., and Zhu, Y.: Using TIMED/SABER nightglow observations to investigate hydroxyl emission mechanisms in the mesopause region, J. Geophys. Res., 117, D02301, https://doi.org/10.1029/2011JD016342, 2012.

Zhu, Y. and Kaufmann, M.: Atomic oxygen abundance retrieved from SCIAMACHY hydroxyl nightglow measurements, Geophys. Res. Lett., 45, 1-9, https://doi.org/10.1029/2018GL079259, 2018. 